\title{
NrCAM Deletion Causes Topographic Mistargeting of Thalamocortical Axons to the Visual Cortex and Disrupts Visual Acuity
}

\author{
Galina P. Demyanenko, ${ }^{1}$ Thorfinn T. Riday, ${ }^{2}$ Tracy S. Tran, ${ }^{4}$ Jasbir Dalal, ${ }^{1}$ Eli P. Darnell, ${ }^{1}$ Leann H. Brennaman, ${ }^{1}$ \\ Takeshi Sakurai, ${ }^{5}$ Martin Grumet, ${ }^{6}$ Benjamin D. Philpot, ${ }^{2,3}$ and Patricia F. Maness ${ }^{1,3}$ \\ Departments of ${ }^{1}$ Biochemistry and Biophysics and ${ }^{2}$ Cell and Molecular Physiology, and ${ }^{3}$ Neuroscience Center, University of North Carolina School of \\ Medicine, Chapel Hill, North Carolina 27599, ${ }^{4}$ Solomon H. Snyder Department of Neuroscience, The Johns Hopkins University School of Medicine, \\ Baltimore, Maryland 21205, 5Department of Psychiatry, Seaver Autism Center, Mount Sinai School of Medicine, New York, New York 10029, and \\ ${ }^{6}$ Department of Cell Biology and Neuroscience, W. M. Keck Center for Collaborative Neuroscience, Nelson Laboratory, Rutgers University, Piscataway, \\ New Jersey 08854
}

NrCAM is a neural cell adhesion molecule of the L1 family that has been linked to autism spectrum disorders, a disease spectrum in which abnormal thalamocortical connectivity may contribute to visual processing defects. Here we show that NrCAM interaction with neuropilin-2 (Npn-2) is critical for semaphorin 3F (Sema3F)-induced guidance of thalamocortical axon subpopulations at the ventral telencephalon (VTe), an intermediate target for thalamic axon sorting. Genetic deletion of NrCAM or Npn-2 caused contingents of embryonic thalamic axons to misproject caudally in the VTe. The resultant thalamocortical map of NrCAM-null mutants showed striking mistargeting of motor and somatosensory thalamic axon contingents to the primary visual cortex, but retinogeniculate targeting and segregation were normal. NrCAM formed a molecular complex with Npn-2 in brain and neural cells, and was required for Sema3Finduced growth cone collapse in thalamic neuron cultures, consistent with a vital function for NrCAM in Sema3F-induced axon repulsion. NrCAM-null mice displayed reduced responses to visual evoked potentials recorded from layer IV in the binocular zone of primary visual cortex (V1), particularly when evoked from the ipsilateral eye, indicating abnormal visual acuity and ocularity. These results demonstrate that NrCAM is required for normal maturation of cortical visual acuity, and suggest that the aberrant projection of thalamic motor and somatosensory axons to the visual cortex in NrCAM-null mutant mice impairs cortical functions.

\section{Introduction}

Neuron-glial-related cell adhesion molecule (NrCAM) is member of the L1 family [L1, close homolog of L1 (CHL1), NrCAM, neurofascin], which function in development of neural connectivity (Maness and Schachner, 2007). The NrCAM gene at chromosome $7 \mathrm{q} 31$ is one of $\sim 100$ candidate genes implicated in autism spectrum disorders (ASDs) (Pinto et al., 2010). NrCAM polymorphisms are associated with ASD subpopulations with obsessive-compulsive behavior, and with mathematical ability (Docherty et al., 2010). NrCAM-null mice (Sakurai et al., 2001)

\footnotetext{
Received Aug. 25, 2010; revised Nov. 2, 2010; accepted Nov. 20, 2010.

This work was supported by grants from Autism Speaks (\#1847) (P.F.M.), by the Simons Foundation, National Science Foundation Grant 0822969, and National Eye Institute Grant R01EY018323 (B.D.P.), by a Seaver fellowship (T.S.), and by National Institutes of Health Grant 5P30NSO45892 to the University of North Carolina at Chapel Hill Neuroscience Center for support of the Confocal Microscopy Facility. Rosa Mino and Alec Tidwell contributed to cell culture analysis. We thank Dr. David Ginty (Johns Hopkins University School of Medicine and Howard Hughes Medical Institute, Baltimore, MD) for reagents and advice.

Correspondence should be addressed to Patricia F. Maness, Department of Biochemistry and Biophysics, University of North Carolina School of Medicine, Campus Box 7260, Chapel Hill, NC 27599. E-mail: srclab@med.unc.edu.

T. S. Tran's present address: Department of Biological Sciences, Rutgers University, Newark, NJ 07102.

J. Dalal's present address: Department of Internal Medicine and Division of Human Nutrition and Metabolic Diseases, University of Texas Southwestern Medical Center, Dallas, TX 75390-8537.

DOI:10.1523/JNEUROSCI.4467-10.2011

Copyright $\odot 2011$ the authors $\quad 0270-6474 / 11 / 311545-14 \$ 15.00 / 0$
}

provide a model for investigating effects of NrCAM deletion on neural circuitry relevant to ASDs. Deletion of NrCAM causes impaired sociability, visual-spatial learning, and sensory gating (Moy et al., 2009b), as well as impulsivity (Matzel et al., 2008) and altered drug reward (Ishiguro et al., 2006). Sensory disturbances in the motor, tactile, and visual systems are common in ASDs and can be manifested in hyper- or hyposensitive responses (Matzel et al., 2008; Baron-Cohen et al., 2009). As most sensory input to the cortex is relayed through the thalamus, thalamocortical circuitry may be perturbed in ASDs. Indeed, MRI studies in autistic patients show widespread thalamocortical disconnectivity affecting visual and sensorimotor systems (Mizuno et al., 2006; Takarae et al., 2007; Mostofsky et al., 2009) and diminished thalamic activity (Hardan et al., 2008).

Accurate topographic targeting of thalamocortical axons from distinct thalamic nuclei to specific neocortical areas is essential for visual cortical function and other sensory modalities. Each projection is topographically organized along rostrocaudal and mediolateral cortical axes (Caviness and Frost, 1980; LopezBendito and Molnar, 2003), which, in the visual cortex, enables visual images to be faithfully represented (Cang et al., 2008). The ventral telencephalon has emerged as an intermediate target where thalamic axons are sorted toward appropriate cortical ar- 
eas by gradients of ephrinAs, netrin-1, and semaphorin 3A (Dufour et al., 2003; Bonnin et al., 2007; Powell et al., 2008). CHL1 interaction with neuropilin-1 mediates semaphorin 3A-induced guidance of thalamic axons to the somatosensory cortex (Wiencken-Barger et al., 2004; Wright et al., 2007; Demyanenko et al., 2010), and cooperates with L1 in thalamic axon targeting to the motor cortex (Demyanenko et al., 2010). Although NrCAM plays a role in patterning of the binocular visual pathway, directing retinal axons across the optic chiasm (Williams et al., 2006), a function in thalamocortical axon guidance has not been investigated. NrCAM differs from other L1 members in mediating repellent responses to neuropilin-2 (Falk et al., 2005) and having a PDZ binding site (Davey et al., 2005; Dirks et al., 2006). Hence, NrCAM might control topographic mapping of thalamic axon subpopulations by a distinct mechanism, and its loss might perturb synaptic targeting in the visual cortex.

We demonstrate that NrCAM mediates repellent guidance to semaphorin $3 \mathrm{~F}$ (Sema3F) in the ventral telencephalon (VTe) through neuropilin-2 (Npn-2), and that NrCAM deficiency causes mistargeting of motor and somatosensory thalamic axon subpopulations to the visual cortex. Decreased responses to visual evoked potentials (VEPs) recorded from layer IV in the binocular zone of NrCAM-null mice suggest that misprojection of thalamic axons to the visual cortex arising from NrCAM loss can affect visual cortical responses such as acuity or binocular vision.

\section{Materials and Methods}

Mice. Wild-type (WT) and homozygous-null NrCAM mutant mice (Sakurai et al., 2001; Ishiguro et al., 2006) were provided by Dr. Martin Grumet (Rutgers University, Piscataway, NJ). These mice were generated by homologous recombination, deleting the fourth exon to remove the translation initiation codon and signal sequence. Homozygotes express no detectable NrCAM protein (Sakurai et al., 2001). Mice on a mixed 129S6/SvEvTac (129S6) $\times$ Swiss Webster (CFW) background were backcrossed to C57BL/ 6 for 7 generations. For our studies, heterozygotes were intercrossed to obtain homozygous NrCAM-null mutants and WT littermates. Neuropilin-2-null mutant mice on a C57BL/6 background were described previously (Giger et al., 2000; Walz et al., 2002), and were generated by intercrossing heterozygotes. E0.5 was defined as the plug date and postnatal day 0 (P0) as day of birth. Animal care and treatment were in accordance with guidelines of the University of North Carolina Institutional Animal Care and Use Committee.

Immunostaining, histology, and immunoblotting. Brains were perfused with $4 \%$ paraformaldehyde (PFA) and postfixed in $4 \%$ PFA, then vibratome sectioned at $60 \mu \mathrm{m}$. Sections were stained with purified $\mathrm{NrCAM}$ rabbit polyclonal IgG (Lustig et al., 2001) (Abcam, ab24344; 1:300) and fluorescein isothiocyanate (FITC)- or tetramethylrhodamine isothiocyanate (TRITC)-conjugated secondary antibodies, and imaged by confocal microscopy as described previously (Wright et al., 2007). For immunohistochemistry, cortical hemispheres were flattened and horizontally sectioned. Sections were then incubated with rabbit polyclonal antibody against serotonin [5 hydroxytryptamine (5-HT), 1:50,000; Immunostar, Inc] for $48 \mathrm{~h}$, then with biotinylated anti-rabbit IgG (Jackson ImmunoResearch Laboratories, Inc). 5-HT immunoreactivity was detected using an Elite ABC Kit and Peroxidase Substrate Kit (Vector Laboratories). For histology, brains were processed for Nissl as described previously (Demyanenko et al., 1999). For embryonic thalamic neuron cultures the following antibodies were used: anti-rat Npn-2 (R\&D Systems; AF567), 1:150; TuJ1 monoclonal antibody (Covance; MMS-435P), 1:500; nestin monoclonal antibody (Developmental Studies Hybridoma Bank), 1:1000; and glial fibrillary acidic protein polyclonal antibody (DAKO), 1:250. Immunoblotting was performed as described previously (Wright et al., 2007).

In situ hybridization. Digoxigenin-labeled riboprobes for NrCAM were generated by in vitro transcription from a pBlueScript plasmid containing mouse NrCAM cDNA (AJ543321; nucleotides 460-1470), in- cluding 9 bases from the $5^{\prime}$ untranslated region. Plasmid pmNrCAM was linearized with EcoRI and transcribed with T7 RNA polymerase for the antisense probe, or with BamHI and transcribed with T3 RNA polymerase for the sense probe, according to manufacturer's protocol (Roche). Digoxigenin-labeled riboprobes for Sema3F (gift from Dr. David Ginty, Johns Hopkins University School of Medicine and Howard Hughes Medical Institute, Baltimore, MD) were generated from the pBS KS vector (Giger et al., 1998). Pixel densities were measured using ImageJ software to assess gradient expression of Sema3F mRNA. In situ hybridization (ISH) was performed in the histology core facility of the Neuroscience Center of University of North Carolina at Chapel Hill. Brains from WT embryos (E14.5) were immersion fixed in 4\% PFA overnight and cryoprotected in sucrose before sectioning horizontally. ISH was performed as described previously (Colbert et al., 1995) and images were captured digitally on a Zeiss Axioplan 2 microscope.

Thalamocortical axon tracing. Retrograde tracing of thalamocortical axons from the cortex was performed by focal injection of 1,1-dioctadecyl-3,3,3-3-tetramethylindocarbocyanine perchlorate (DiI) and 4,4-dihexadecyl aminostyryl $N$-methylpyridinium iodide (DiA) (Invitrogen) (5-10\% in $\mathrm{N}, \mathrm{N}$-dimethylformamide) in one or two distinct cortical areas of living P5 mice anesthetized by hypothermia. Injections were made with capillary micropipettes connected to a Picospritzer II. Mice were fixed by transcardial perfusion with $4 \%$ paraformaldehyde $48 \mathrm{~h}$ later. Forebrains were vibratome sectioned in the coronal plane (100 $\mu \mathrm{m})$. Injection sites were monitored microscopically and only those injections restricted to the neocortex, without entering the white matter, were analyzed. The location and position of injection sites, and position of thalamic nuclei were identified by DAPI $\left(4^{\prime}, 6^{\prime}\right.$-diamidino-2phenylindole dihydrochloride) nuclear staining and comparison to atlas coordinates (Franklin and Paxinos, 1997). Cortical injections of DiI/DiA in live postnatal mice predominantly label thalamocortical axons by retrograde tracing from layer IV with minimal anterograde labeling of corticofugal axons (Dufour et al., 2003; Torii and Levitt, 2005; Wright et al., 2007; Little et al., 2009; Demyanenko et al., 2010).

For anterograde tracing, brains of WT, NrCAM, and Npn-2 mutant embryos (E15.5) were fixed in $4 \%$ PFA overnight at $4^{\circ} \mathrm{C}$. After hemidissection, crystals of DiA (rostral) or DiI (caudal) were inserted into the dorsal thalamus (DT). After diffusion for 2-4 weeks at room temperature, brains were vibratome sectioned $(100 \mu \mathrm{m})$ in the coronal plane. Sections were mounted in Vectashield and imaged using epifluorescence or confocal microscopy. The size and position of the crystals with respect to the thalamic eminence (TE), where axons leave the diencephalon and enter the VTe, were verified microscopically. Acceptable injections were within $100 \mu \mathrm{m}$ of the TE for the rostral DT and $300 \mu \mathrm{m}$ for the caudal DT. The data were analyzed as reported previously (Dufour et al., 2003; Wright et al., 2007). Data were graphed with the $x$-axis depicting the position of labeled axons in sections along the rostrocaudal axis of the ventral or dorsal telencephalon relative to the first section of the TE (0 $\mu \mathrm{m})$. Because of slight differences in total number of sections among hemispheres, section numbers were normalized with respect to the distance from the TE $(0 \mu \mathrm{m})$. The $y$-axis (frequency) represented the percentage of hemispheres containing DiI-labeled axons for each genotype. The normalized section number exhibiting the greatest frequency of labeled axons was set at $100 \%$ for each genotype. The distance $(\mu \mathrm{m})$ of the caudal-most labeled section from the TE was determined for each case, then means were calculated and compared by Student's $t$ test $(p<0.05)$.

Growth cone collapse assay. Dissociated cultures of thalamic embryonic (E14.5) neurons were prepared from WT and NrCAM-null littermates as described previously (Demyanenko et al., 2010), plated in fibronectincoated Lab-Tek chamber slides in 10\% fetal bovine serum and DMEM, and the next day the medium was changed to Neurobasal medium with B27 supplement and glutamate $(25 \mu \mathrm{M})$. Marker immunostaining after $1 \mathrm{~d}$ in culture showed that these cultures contained $\sim 60 \%$ Tuj1-positive neurons, $\sim 50 \%$ nestin-positive immature neurons, and $\sim 40 \%$ glial fibrillary associated protein-positive glia. Only the TuJ1-positive cells had typical neuronal morphology with multiple processes tipped by large growth cones emerging from cell bodies. After $42 \mathrm{~h}$, cells were treated with normal human IgG or Sema3F fused to human Fc (Sema3F-Fc; R\&D Systems) (30 nM) for $30 \mathrm{~min}$. Cells were fixed with $4 \%$ paraformal- 
dehyde and permeabilized with $0.2 \%$ Triton X-100 for 5 min. After washing, cells were treated with rhodamine-conjugated phalloidin (Invitrogen; 1:40) for $30 \mathrm{~min}$ to visualize F-actin in the growth cone. Cells were mounted in Vectashield and growth cone morphology was scored under epifluorescent illumination. Only cells with neuronal morphology including multiple processes were analyzed. Growth cones were scored as collapsed if they had a bullet-shaped morphology, and uncollapsed if they were well spread with numerous filopodia as described previously (Demyanenko et al., 2010).

Cell surface coclustering of NrCAM and neuropilin-2. Cell surface coclustering was performed as previously reported for CHL1 and Npn-2 (Wright et al., 2007). The mouse neuroblastoma cell line Neuro2A was plated on fibronectin and poly-D-lysine-coated Lab-Tek dishes in DMEM-10\% calf serum (CS). These cells express NrCAM, Npn-2, and PlexinA3 by Western blotting (data not shown). To cluster surface Npn-2, cells (10,000 cells) were incubated with Npn-2 goat polyclonal antibody AF567 (40 $\mu \mathrm{g} / \mathrm{ml}$; R\&D Systems) against extracellular determinants at $4^{\circ} \mathrm{C}$ for $20 \mathrm{~min}$, washed in ice-cold DMEM-HEPES without CS, then incubated with mouse anti-goat IgG $(10 \mu \mathrm{g} / \mathrm{ml})$ in DMEM- $25 \mathrm{mM}$ HEPES for $30 \mathrm{~min}$ on ice (4C). After washing with DMEM, cells were incubated in DMEM-10\% CS for $1 \mathrm{~h}$ at $37^{\circ} \mathrm{C}$ then fixed with $4 \%$ PFA for $15 \mathrm{~min}$. After washing, cells were blocked in $10 \%$ donkey serum for $1 \mathrm{~h}$ at room temperature, and incubated with NrCAM rabbit polyclonal antibody $(10 \mu \mathrm{g} / \mathrm{ml})$ against extracellular determinants for $1 \mathrm{~h}$. As control, normal goat IgG $(40 \mu \mathrm{g} / \mathrm{ml})$ in DMEM- $10 \%$ CS and normal rabbit IgG $(10 \mu \mathrm{g} / \mathrm{ml})$ in $10 \%$ normal donkey serum were substituted. All cells were incubated with FITC 488-DyLight donkey anti-mouse IgG (Jackson ImmunoResearch Laboratories, Inc) and TRITC-donkey anti-rabbit IgG (Jackson ImmunoResearch Laboratories, Inc) (1:100) for $1 \mathrm{~h}$, washed, and mounted in Vectashield. Cells were imaged using Zeiss 510 confocal microscope, and scored for clustering of Npn-2 and NrCAM into patches or caps in merged images. The percentage of Npn-2-positive cells exhibiting coclustering of NrCAM in patches and/or caps was quantified.

Coimmunoprecipitation. Brains of WT embryos (E15.5) were lysed in radioimmunoprecipitation assay buffer $[20 \mathrm{~mm}$ Tris, $\mathrm{pH}$ 7.0, $0.15 \mathrm{M}$ $\mathrm{NaCl}, 5$ mм EDTA, 1 mм EGTA, 1\% Nonidet P-40, 1\% deoxycholate, $0.1 \%$ SDS, $200 \mu \mathrm{M} \mathrm{Na} \mathrm{NO}_{4}, 10 \mathrm{~mm} \mathrm{NaF}, 1 \times$ protease inhibitors (Sigma)], clarified by centrifugation, and protein concentration was determined by bicinchoninic acid (ThermoFisher Scientific). NrCAM was imunoprecipitated from $1 \mathrm{mg}$ of brain homogenate using NrCAM IgG (1 $\mu \mathrm{g}$ ) and protein $\mathrm{A} / \mathrm{G}$ agarose. Nonimmune rabbit IgG was used as a control. Immunoprecipitated proteins and brain lysates $(75 \mu \mathrm{g})$ were separated by SDS-PAGE, transferred to nitrocellulose, and Western blotted using Npn-2 (1:500) or $\mathrm{NrCAM}$ (1:500) antibodies. Blots were developed using enhanced chemiluminescence (ThermoFisher Scientific) and exposed to film.

Labeling and quantification of retinogeniculate projections. WT and NrCAM-null littermates (P10) were anesthetized with isoflurane, and injected with Alexa Fluor 488-conjugated cholera toxin subunit B in one eye and Alexa Fluor 594-conjugated cholera toxin subunit B in the other eye (Alexa fluors; Invitrogen). At P12, mice were perfused with $4 \%$ paraformaldehyde; brains were sectioned at $100 \mu \mathrm{m}$, and mounted. Fluorescent images of brain sections containing the dorsal lateral geniculate nucleus (dLGN) were examined on a Zeiss Axioplan microscope, and captured using universal gains and exposures on a Zeiss Axiocam color CCD camera. Unmodified images of the dLGN were analyzed in Adobe Photoshop using the multithreshold protocol used by (Stevens et al., 2007) based on the methods described by Torborg et al. (2005). The multithreshold protocol provides a range of signal to background levels for analysis of the size of the ipsilateral axon area (termed "ispilateral patch") relative to the total size of the dLGN, as well as any overlap between the ipsilateral patch and the contralateral axon targeting area in the dLGN. The pixel areas of the modified images were measured in Image for each threshold level, delivering values for both ipsilateral and overlap area. Total dLGN area was measured by selecting the unmodified contralateral image in ImageJ and measuring total area. Mean ipsilateral area/dLGN area for each genotype was compared at each threshold level by $t$ test $(p<0.05)$. The distance of the lateral border of the ipsilateral patch at its widest portion from the lateral border of the dLGN was measured and expressed as a percentage of the width of the dLGN at the same location. The length of the ipsilateral patch from the dorsomedial to ventrolateral border was expressed as a percentage of the length of the dLGN. Means were compared by the $t$ test $(p<0.05)$.

Visual evoked potential recording. Male and female mice (P27) were anesthetized with ketamine/xylazine (120 mg:9 mg/kg) and $0.25 \%$ bupivacaine (Hospira) applied as a local anesthetic to the scalp incision site. Tungsten microelectrodes (FHC) with impedances of $0.3-0.5 \mathrm{M} \Omega$ were implanted in the binocular visual cortex $[ \pm 3.0 \mathrm{~mm}$ mediolateral $(\mathrm{ML})$ to lambda, and $0.42 \mathrm{~mm}$ dorsoventral to brain surface). Recording electrodes, silver reference electrodes $( \pm 2.0 \mathrm{~mm} \mathrm{ML},-1.0 \mathrm{~mm}$ anteroposterior to bregma, placed on brain surface), and holding post (resting on the skull surface anterior to bregma) were all secured to the skull with cyanoacrylic (Henkel). Mice were habituated to the restraint device $24 \mathrm{~h}$ before the recording session at P27. All recordings were performed blind to genotype. Awake mice were placed $20 \mathrm{~cm}$ from a 21 inch cathode ray tube monitor $\left(63 \mathrm{~cd} / \mathrm{m}^{2}\right)$ and presented with 160 visual stimuli per condition. A trough to peak VEP amplitude was determined from the averaged visual response. Monocular and binocular visual stimuli consisted of full-field square counterphase sine gratings $\left(45^{\circ}\right.$ or $\left.135^{\circ}\right)$ of 0.05 cycles/ degree (cpd) and $0.3 \mathrm{cpd}$ at $100 \%$ contrast (Vision Research Graphics). All recordings were amplified $1000 \times$, and high and low band filters set to $0.1 \mathrm{~Hz}$ and $100 \mathrm{~Hz}$, respectively (Grass Instruments). Data were digitized and acquired in Spike2 (Cambridge Electronic Design).

\section{Results}

\section{NrCAM is expressed in the developing thalamocortical pathway}

To investigate the role of NrCAM during development of the topographic thalamocortical axon projection, NrCAM expression was analyzed by immunostaining at embryonic days 14.5 (E14.5) and E16.5, and at P5 (Fig. 1A-E). From E14.5-16.5, thalamic axons navigate from the DT through the VTe en route to the cortex. At E14.5 and E16.5, NrCAM was robustly expressed on fibers within the DT and crossing the VTe (Fig. 1A,D). NrCAM was also expressed in the cortex, where it was most evident within the intermediate zone (IZ) and marginal zone (MZ), with low levels in the ventricular zone (VZ) (Fig. $1 B, E$ ). NrCAM expression was prominent in the cortex at P5, where it was predominant in deep layers (IV-VI) (Fig. $1 F$ ). No labeling was observed with nonimmune IgG, as shown at E14.5 in the cortex (Fig. $1 C$ ). Immunoblotting for $\mathrm{NrCAM}$ in lysates of mouse forebrain confirmed its expression from E16.5 through P5, and showed persistently elevated levels at later stages of maturation (Fig. 1G). $\mathrm{NrCAM}$ antibodies recognized the major $140 \mathrm{kDa}$ NrCAM protein, corresponding to furin-cleaved $\mathrm{NrCAM}$, and its $60 \mathrm{kDa}$ fragment in brain (Sakurai et al., 2001; Conacci-Sorrell et al., 2005). Full-length NrCAM $(200 \mathrm{kDa})$ protein is rarely observed except in transfected cells (Sakurai et al., 1997; Conacci-Sorrell et al., 2005).

In situ hybridization to detect NrCAM mRNA was performed on serial horizontal sections through the DT of E14.5 and E16.5 embryos, and P5 mice ( $n=3$ per stage). Results showed that NrCAM transcripts were differentially expressed along both rostrocaudal and dorsoventral axes of the embryonic DT (Fig. $1 H-L)$. Although thalamic nuclei are not fully developed or identifiable in E14.5-E16.5 embryos, NrCAM transcripts were more abundant in discrete regions of the rostral DT, where anlage of the ventroanterior (VA) and ventrolateral (VL) thalamic nucleus arise, as well as in more caudolateral regions of the DT (Fig. $1 H, K$, arrows). Notably, NrCAM was not expressed in cells within the VTe. This pattern of NrCAM transcripts was different from but partly overlapping with that of L1 (Demyanenko et al., 2010) and CHL1 (Wright et al., 2007) in the developing DT. High levels of NrCAM transcripts were also evident in the dorsal telencephalon (DTe, cortex) at E14.5-E16.5, most prominently in the cortical plate $(\mathrm{CP})$ (Fig. $1 I, K)$. Control staining with a sense 
probe generated from the same plasmid showed no labeling at E14.5 (Fig. 1J) or other stages. At P5, NrCAM mRNA was observed at highest levels in deep layers of the neocortex and in the hippocampus, but at low levels in the DT (Fig. $1 L$ ).

NrCAM is required for correct topography of thalamocortical projections to motor and somatosensory cortical areas

Topography of thalamocortical projections is organized such that rostromedial thalamic neurons project to more rostral areas of the neocortex and caudolateral thalamic neurons project to more caudal areas (Caviness and Frost, 1980). To investigate a role for NrCAM in thalamocortical axon targeting, the projections of thalamic axons were analyzed by retrograde tracing from primary motor and sensory neocortical areas to different DT nuclei in WT and NrCAM-null littermates at P7, when thalamocortical topographic connectivity is completed (Agmon et al., 1995). Carbocyanine dyes (DiI or DiA) were singly or dually injected into the primary visual (V1), somatosensory (S1), or motor (M1) cortex of live, anesthetized P5 mice, and analyzed at P7. DiI/DiA injections into different cortical areas labeled the cell bodies of thalamic neurons in DT nuclei by retrograde tracing, as documented in supplemental Figure $1 N$ (available at www.jneurosci.org as supplemental material). Injections of $\mathrm{DiI} / \mathrm{DiA}$ were carefully screened for restricted localization within the cortical plate and absence from the white matter. Injections (single or dual) into V1 of WT mice labeled cells in the dLGN (10 of 10 injections) but not in other DT nuclei, such as the VL or ventrobasal (VB) nuclei (Fig. 2C,D; supplemental Fig. $2 A-I$, available at www.jneurosci. org as supplemental material). Injections of DiI into M1 of WT mice labeled only VA and VL nuclei (13 of 13) (Fig. 2E). Injections into S1 of WT mice labeled only VB nuclei (13 of 13). Dual injection of DiA into S1 and DiI into V1 specifically labeled VB (green) or dLGN (red) nuclei, respectively, with no mixing of labels (Fig. $2 F)$. WT thalamocortical axonal trajectories are summarized in Figure $2 A$.

In NrCAM-null mutant mice injections into $\mathrm{V} 1$ resulted in inappropriate labeling of VA and/or VL (12 of 19) (Fig. $2 H$, I; supplemental Fig. $1 C-H$, available at www.jneurosci.org as supplemental material) as well as VB nuclei (16 of 19) (Fig. 2 J; supplemental Fig. $1 \mathrm{~J}$, available at www.jneurosci.org as supplemental material). In addition, normal labeling was observed in the dLGN (19 of 19) (Fig. 2J,O; supplemental Fig. $1 \mathrm{~J}, L$, available at www.jneurosci.
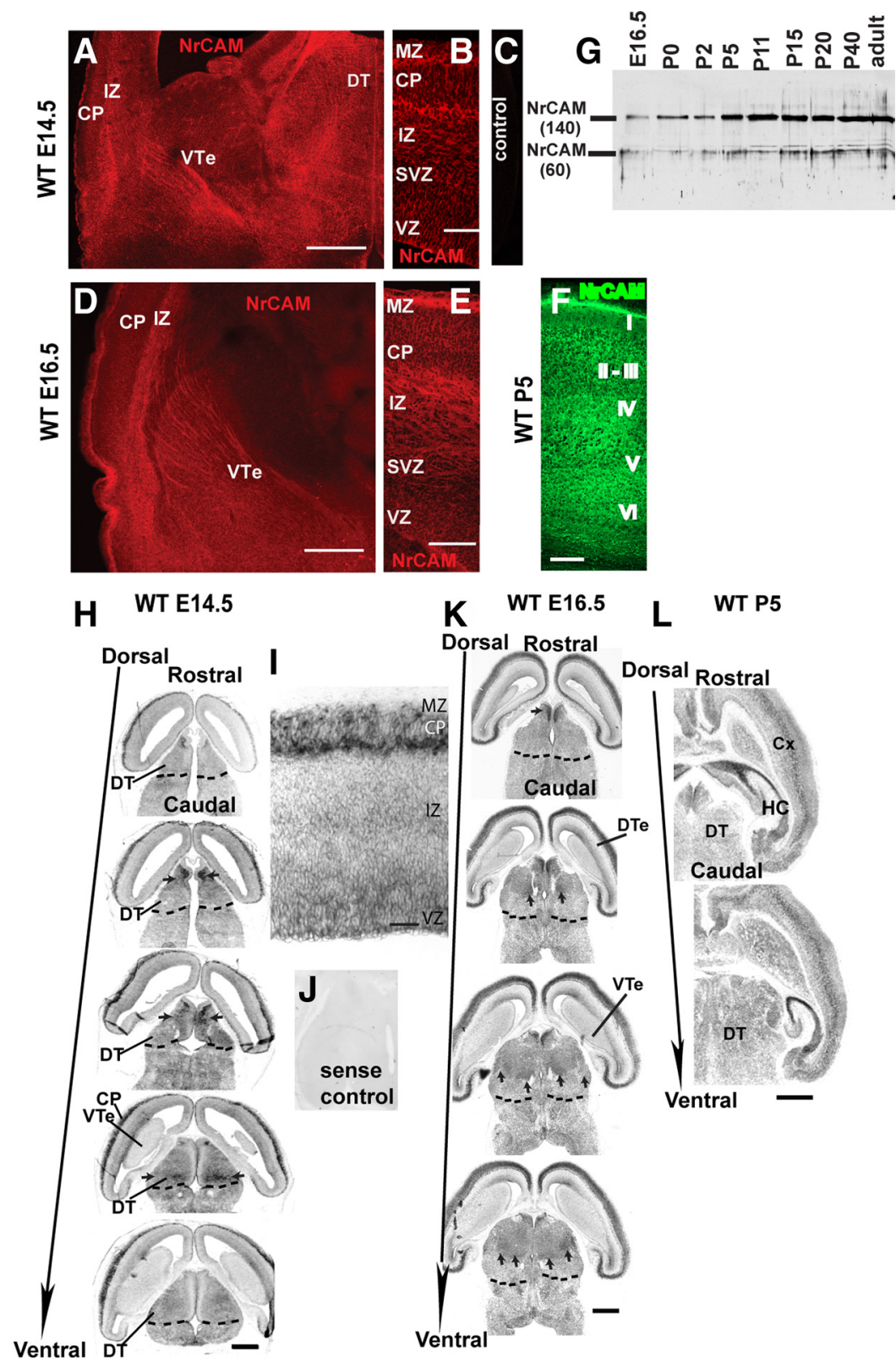

K WT E16.5 L WT P5

Figure 1. NrCAM is expressed in the developing thalamocortical pathway. $\boldsymbol{A}$, Immunofluorescence staining for NrCAM in a midcoronal section (to best observe the entire thalamocortical pathway) of WT mouse embryonic brain (E14.5) during projection of thalamic axons to the neocortex visualized by confocal microscopy. NrCAM protein was evident in the DT, VTe, IZ, MZ, and CP. $\boldsymbol{B}$, NrCAM localization in the visual cortex of WT embryos (E14.5). NrCAM staining was most prominent in the IZ and MZ, with lower levels in the VZ. C, No staining was observed with nonimmune lgG (control) (E14.5). D, Immunofluorescence staining for NrCAM in a mid-coronal section of E16.5 WT brain visualized by confocal microscopy. NrCAM protein is prominent in the DT and VTe, and is also present in IZ and CP. E, NrCAM localization in the visual cortex of WT mouse embryonic brain (E16.5) visualized by confocal microscopy. NrCAM staining was most prominent in fibers crossing the VTe, and in the cortical IZ and MZ. F, NrCAM localization in the visual cortex of postnatal WT mice (P5). NrCAM staining was prominent in all cortical layers with highest levels in deep layers (IV-VI). G, Expression of NrCAM (major $140 \mathrm{kDa}$ form and minor $60 \mathrm{kDa}$ cleavage fragment) during development as shown by immunoblotting of WT mouse forebrain lysates $(50 \mu \mathrm{g})$ at embryonic, postnatal and adult stages. $\boldsymbol{H}, \boldsymbol{K}, \boldsymbol{L}$, In situ hybridization shows NrCAM transcripts in WT embryos (E14.5, E16.5, and P5) in serial horizontal sections (to best observe the DT) along the dorsoventral axis. $\boldsymbol{H}, \boldsymbol{K}$, At E14.5 and E16.5 NrCAM transcripts were most abundant in discrete rostral and caudal regions of the DT (arrows), and in the CP, but not in the VTe. Dashed lines delineate the caudal DT boundary. L, At P5 NrCAM transcripts were high in the deep layers of the cortex and in the hippocampus, and low in the DT. I, NrCAM transcripts in the visual cortex (E14.5) showed highest levels in the deep (P. J, No labeling at E14.5 was obtained using the control sense riboprobe. CX, cerebral cortex; $H C$, hippocampus; SVZ, subventricular zone. Scale bars: $(\boldsymbol{A}, \boldsymbol{D}, \boldsymbol{H}, \boldsymbol{J}-\boldsymbol{L}), 500 \mu \mathrm{m} ;(\boldsymbol{B}, \boldsymbol{E}, \boldsymbol{F}), 100 \mu \mathrm{m} ;(\boldsymbol{I}), 50 \mu \mathrm{m}$.

org as supplemental material). Injections into M1 of NrCAMnull mutants always resulted in normal labeling of VA/VL nuclei (19 of 19) (Fig. $2 \mathrm{~K}$ ). Dual injection of DiA into M1 and DiI into $\mathrm{V} 1$ resulted in appropriate DiA labeling (green) and inappropri- 

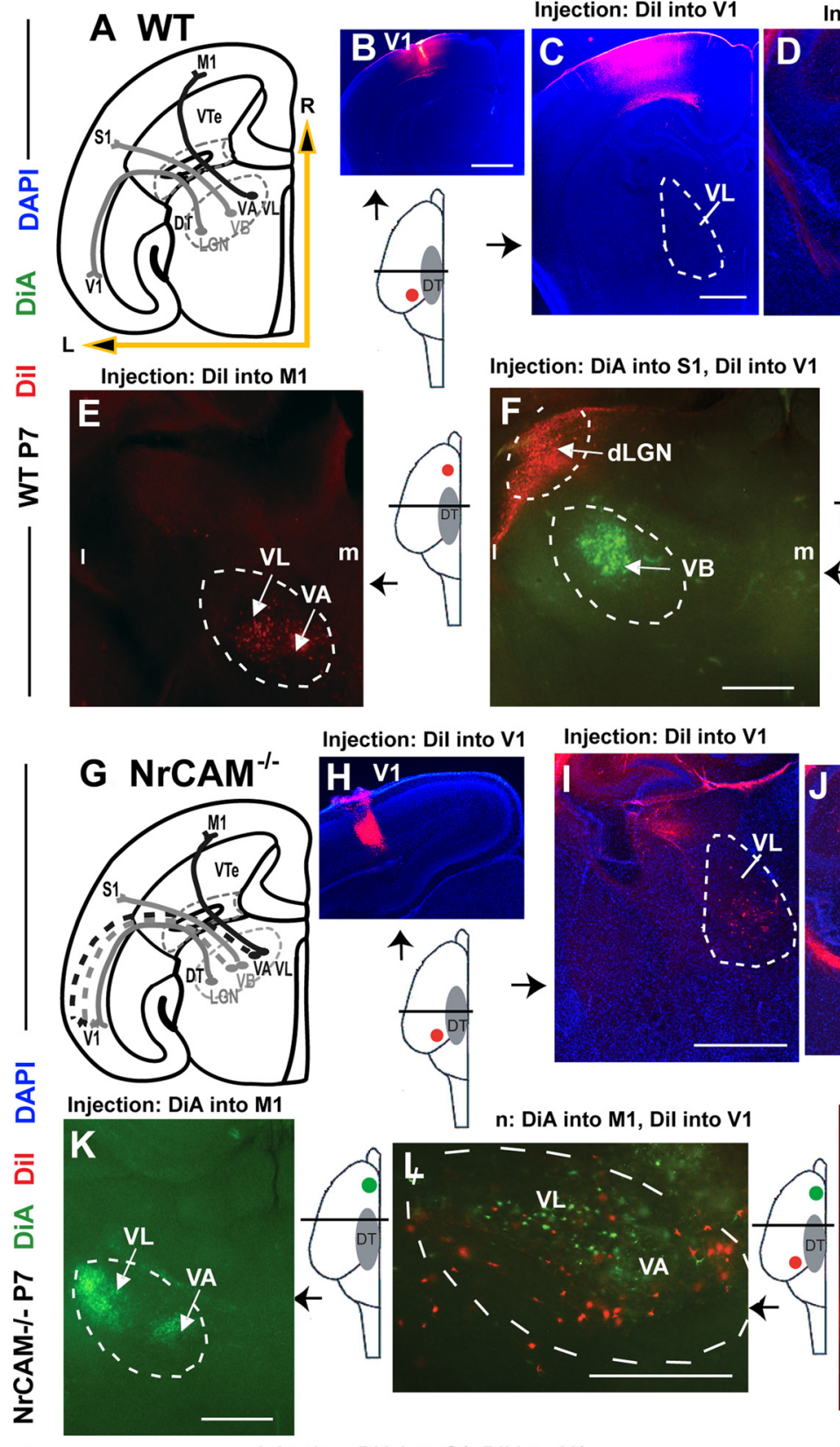

Injection: DiA into S1, Dil into V1
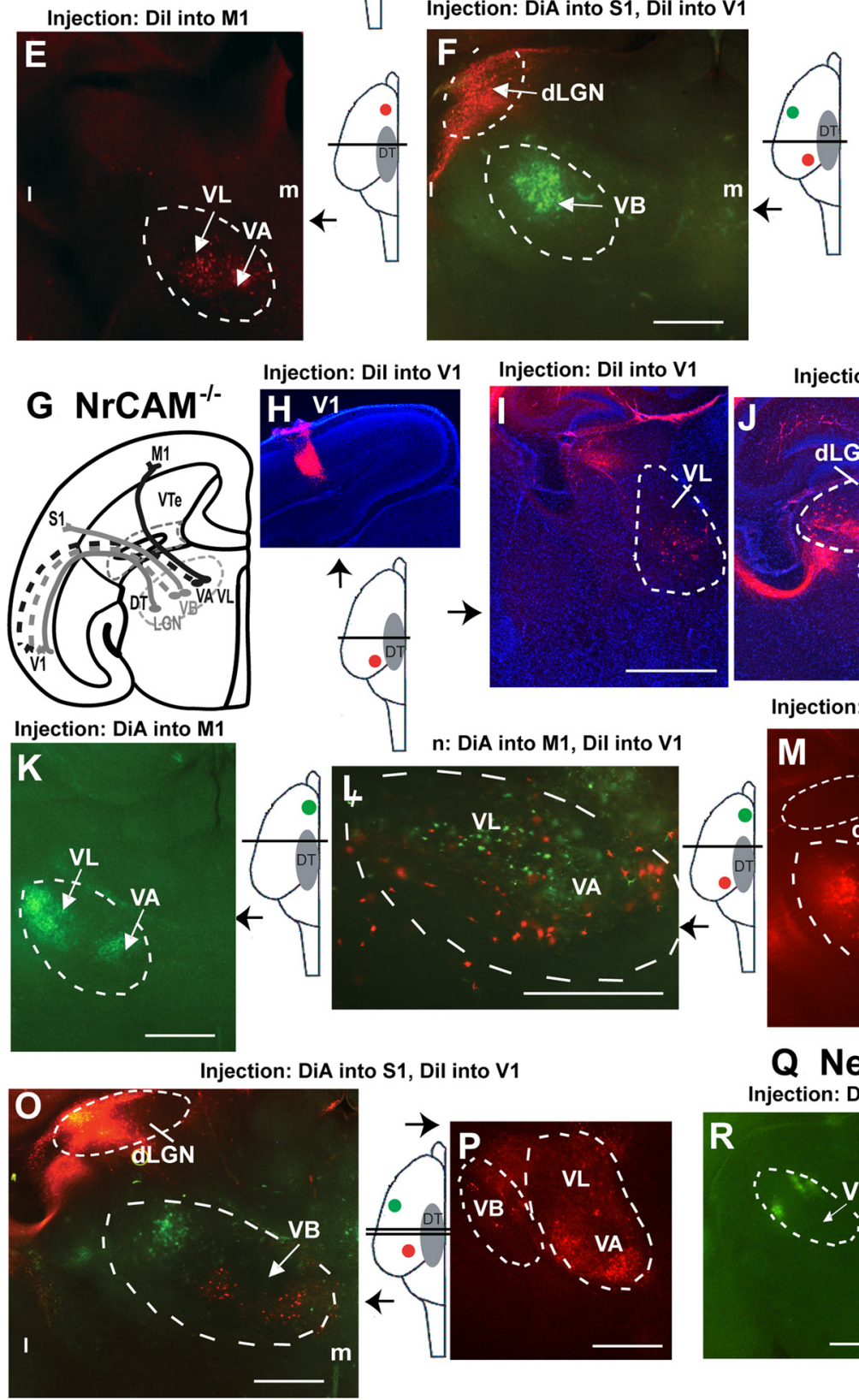

Injection: Dil into V1

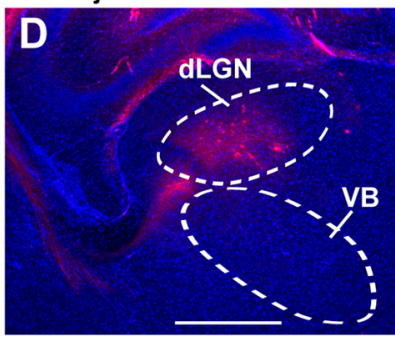

Injection: Dil into V1

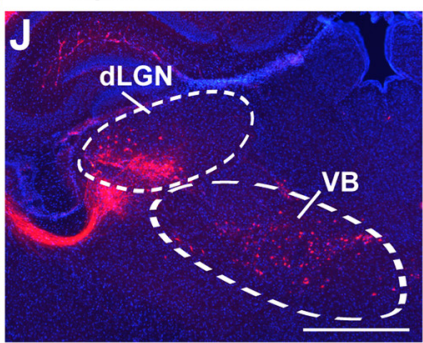

Injection: Dil into S1
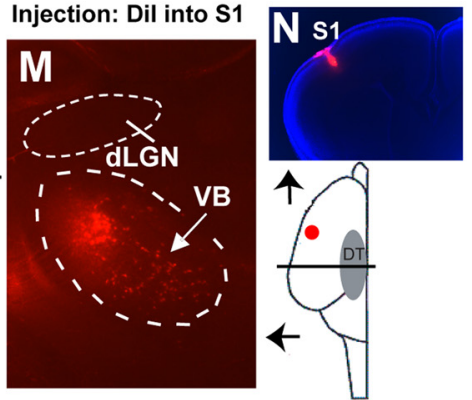

Q Neurofascin-

Injection: DiA into S1, Dil into V1

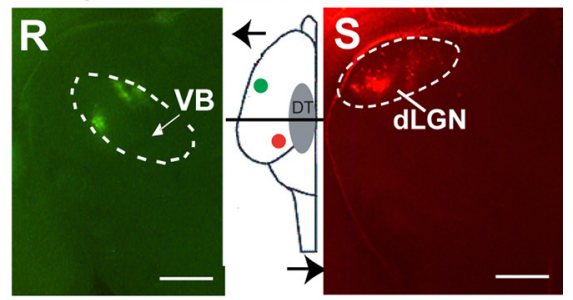

Figure 2. Projections of motor and somatosensory thalamic axons misproject caudally to the visual cortex in NrCAM-null mutant mice (P5). $A$, Scheme illustrating the final thalamocortical map in WT mice (P5). Axons from VA/VL DT nuclei project to M1; axons from VB project to S1; axons from the dLGN project to V1. The orientation of all images in Figure 2 are indicated in $A(R$, rostral; $L$, lateral). Injection site and section plane of each image are schematically illustrated. $\boldsymbol{B}-\boldsymbol{D}$, Retrograde axon tracing in WT mice following injection of Dil into V1 at P5 and analysis at P7. $\boldsymbol{B}$, Dil injection site in V1 for experiment shown in Cand $\boldsymbol{D}$. C, No labeling of cell soma in VL. D, Appropriate labeling of cell soma in the dLGN and no labeling of VB nuclei. $\boldsymbol{E}$, Retrograde axon tracing in WT mice (P5) following injection of Dil into M1 shows appropriate labeling of cell soma in VA/VL nuclei. $F$, Retrograde axon tracing in WT mice (P5) following dual injections of DiA into S1 and Dil into V1 shows appropriate labeling of cell soma in the VB and dLGN, respectively. G, Scheme illustrating altered thalamocortical topography in NrCAM-null mutant mice (P5). Contingents of thalamocortical axons from VA/VL and VB nuclei project inappropriately to V1, while some contingents project normally to M1 and S1. dLGN axons project appropriately to V1. $H$-J, Retrograde axon tracing in NrCAM-null mutant mice following injection of Dil into V1 at P5 and analysis at P7. $\boldsymbol{H}$, Dil injection site in V1 for experiment shown in I and $J . I$, Inappropriate labeling of cell soma located within VL. J, Appropriate labeling of cell soma located within the dLGN and inappropriate labeling of cell soma in VB nuclei. $\boldsymbol{K}$, Retrograde axon tracing in NrCAM-null mice (P5) following DiA (Figure legend continues.) 
ate DiI labeling (red) of VA/VL nuclei (Fig. $2 L$ ). Single injections into $\mathrm{S} 1$ (Fig. $2 \mathrm{~N}$ ) resulted in normal labeling of only VB nuclei (15 of 15) (Fig. 2M). Dual injection of DiA into S1 and DiI into $\mathrm{V} 1$ resulted in appropriate DiA labeling (green) of VB, but inappropriate DiI labeling (red) of VB (Fig. 2O) and VA/VL (Fig. 2 P). This confirmed the inappropriate labeling of VB and VA/VL resulting from single V1 injections. Single axons from dual injections were not double-labeled, indicating that mistargeting of mutant axons did not arise from axon collaterals. Chi Square analysis confirmed that there were significant differences in the misprojection of NrCAM-null mutant axons from VA/VL to V1 $\left(\chi^{2}=10.77, p<0.01\right)$ and from VB to V1 $\left(\chi^{2}=18.78, p<\right.$ $0.001)$, but not in any other case ( $\chi^{2}$ undefined).

Although NrCAM can bind heterophilically to neurofascin, another L1-CAM family member (Volkmer et al., 1996; Pruss et al., 2004) expressed in the thalamocortical pathway, retrograde axon tracing in neurofascin-null mutant mice (P5) revealed no deviations in the projections of thalamic axons retrogradely traced by DiI or DiA injections into S1 (10 of 10), V1 (4 of 4) (Fig. $2 R, S$ ), or M1 (4 of 4 ) (Fig. $2 R, S$ ). Thus, the thalamocortical axon mapping defects observed in NrCAM-null mutants were not recapitulated in neurofascin mutants, suggesting that the topography of these projections most likely does not depend on NrCAM interactions with neurofascin.

In conclusion (Fig. 2G), results of retrograde axon tracing experiments in NrCAM-null mutant mice (P5) suggested that loss of NrCAM causes a subset of thalamic axons from motor and somatosensory nuclei to shift caudally and inappropriately target the visual cortex.

\section{NrCAM is required for guidance of thalamic axon subpopulations at the ventral telencephalon}

To investigate whether the observed mistargeting was due to misguidance of TC axons at the intermediate axon sorting target, the VTe, anterograde tracing of DT axons was performed in WT and NrCAM-null mutant embryos (E15.5). After fixation, DiA was injected into the rostral third of the DT, where VA/VL nuclei develop, and DiI into the caudal third of the DT, where the dLGN arises (Fig. 3 , schemes). After 4 weeks the distribution of axons in the VTe was analyzed in serial sections along the rostrocaudal axis. Normally, rostral DT axons project rostrally through the VTe, while caudal DT axons project caudally (Dufour et al., 2006). At the TE, where thalamocortical axons leave the diencephalon and enter the VTe, labeled rostral (green) and caudal (red) DT axons were clearly segregated in both WT and NrCAM-null embryos (Fig. 3A,D). No differences were observed in axon fasciculation, or in segregation of labeled rostral and caudal thalamocortical axons along the mediolateral axis of the VTe in NrCAM-null mutant embryos.

Within the VTe, rostral DT axons in NrCAM-null embryos were shifted in the caudal direction compared with WT, as shown

$\leftarrow$

(Figure legend continued.) injection into M1 shows normal labeling of VA/VL. L, Retrograde axon tracing in NrCAM-null mice (P5) following dual injections of DiA into M1 and Dil into V1 shows appropriate DiA labeling of cell soma in VA/VL and inappropriate Dil labeling of VA/VL. $\boldsymbol{M}$, Retrograde axon tracing in NrCAM-null mutants (P5) following Dil injection into S1 shows normal labeling of VB and no labeling of dLGN. $\boldsymbol{N}$, Dil injection site in $\mathrm{S} 1 \mathrm{for}$ experiment shown in $\boldsymbol{M} . \mathbf{0}, \boldsymbol{P}$, Retrograde axon tracing in NrCAM-null mice (P5) following dual injections of DiA into S1 and Dil into V1 shows inappropriate Dil labeling of cell soma in VB $(\boldsymbol{O}, \boldsymbol{P})$ and VA/VL $(\boldsymbol{P})$, as well as appropriate Dil labeling of dLGN (0) and DiA labeling of VB (0). Q-S, Retrograde axon tracing in Neurofascin-null mutant mice (P5) following dual injections of DiA into S1 and Dil into V1 shows appropriate labeling of VB $(\boldsymbol{R})$ and $\operatorname{dLGN}(\boldsymbol{S})$. I, lateral; $\mathrm{m}$, medial; VPL, ventroposterior lateral; VPM, ventroposterior medial. Scale bars, $500 \mu \mathrm{m}$ in all panels. by the presence of DiA-labeled axons in caudal sections of NrCAM mutants (Fig. 3E) where labeled axons were not observed in WT (Fig. 3B). The distribution of labeled rostral DT axons present along the rostrocaudal axis of the VTe demonstrated that NrCAM-null axons were shifted caudally (Fig. 3E-J). The mean distance of caudal-most sections in the VTe containing labeled rostral DT axons from the TE was significantly greater in NrCAM mutants than WT, indicating that they were significantly shifted in the caudal direction (Fig. $3 E, G, H$ ). Axons from the rostral DT that had arrived in the dorsal telencephalon of NrCAM-null embryos (E15.5) also displayed a significant caudal shift in their distribution compared with WT (Fig. 3 F, I,J), demonstrating that misguidance was maintained in the developing cortex. A similar analysis of DiI-labeled caudal DT axons showed no significant differences in rostrocaudal distribution in the VTe or cortex of NrCAM mutants at E15.5 compared with WT (data not shown).

\section{NrCAM colocalizes with the Sema3F receptor neuropilin-2 in the thalamocortical pathway}

To investigate whether NrCAM might cooperate with Npn-2 to regulate thalamic axon responses to Sema3F, Npn-2, and Sema3F expression was analyzed in WT embryos during the major period of thalamocortical axon outgrowth (E14.5). Double immunostaining in rostral sections through the DT showed that Npn-2 was prominently expressed in the DT and colocalized extensively with NrCAM (Fig. 4A-I). NrCAM and Npn-2 were present on cells (Fig. 4D-F) and fibers (Fig. 4G-I) and largely colocalized in the rostral DT except in the extreme medial area (Fig. 4D-F). In more caudal sections (Fig. $4 J-L$ ) NrCAM and Npn-2 were less highly expressed in the DT (Fig. $4 J-L$ ), but clearly colocalized on DT axons, where they emerged from the TE and navigated across the VTe (Fig. 4M-O, arrows). The expression of Sema3F, a principal ligand for Npn-2, was evaluated by in situ hybridization in WT E14.5 embryos. Sema3F transcripts were abundant in the VTe (Fig. 4P). Sema3F transcripts were also evident in the cortex, especially in the CP (Fig. 4Q). Control labeling with the sense probe was low in both VTe and cortex (Fig. $4 R$ ). The observed pattern of Sema3F mRNA expression was in accord with studies in developing rat VTe and cortex (Tamamaki, 2002). Importantly, measurement of pixel density revealed an ascending rostrocaudal gradient of Sema3F mRNA in the VTe (Fig. 4S). Thus, the gradient of Sema3F in the VTe of E14.5 embryos could potentially function to repel thalamic axons expressing NrCAM and Npn-2 from caudal regions of the VTe.

\section{Neuropilin-2 mediates guidance of thalamic axons in the ventral telencephalon}

To investigate whether Npn-2 was involved in thalamocortical axon guidance, thalamic axons were anterogradely labeled in homozygous Npn-2-null mutant embryos (E15.5) by injecting DiA into the rostral DT and DiI into the caudal DT after fixation (Fig. 5 schemes). Rostral and caudal DT axons were clearly segregated as they emerged from the TE in both Npn-2 heterozygous controls and Npn-2-null embryos, and showed no evidence of altered fasciculation (Fig. 5A,D). Analysis of the distribution of labeled axons in the VTe revealed that rostral DT axons in Npn2-null embryos were shifted caudally compared with Npn-2 heterozygotes, as shown by the presence of DiA-labeled axons in more caudal sections of Npn-2 mutants (Fig. $5 E$ ), and by the caudal shift in distribution of rostral DT axons in VTe (Fig. $5 G, H$ ) and DTe (Fig. $5 F, I, J$ ). The mean distance of caudal-most sections containing labeled rostral DT axons in the VTe was sig- 

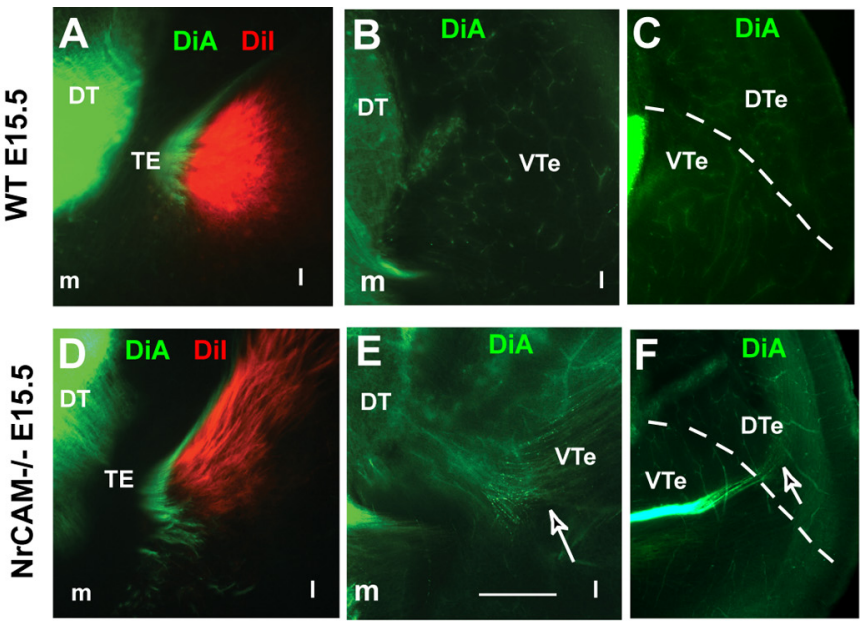

Analysis of Rostral Axons (DiA) in the VTe

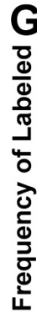

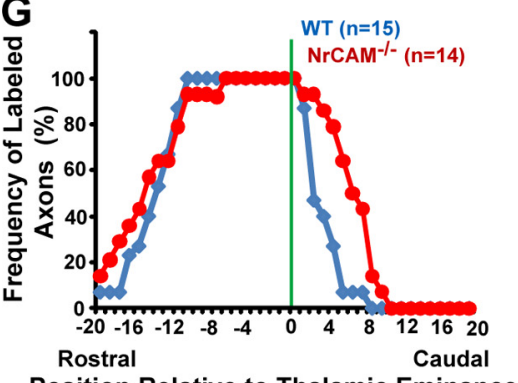

Position Relative to Thalamic Eminance
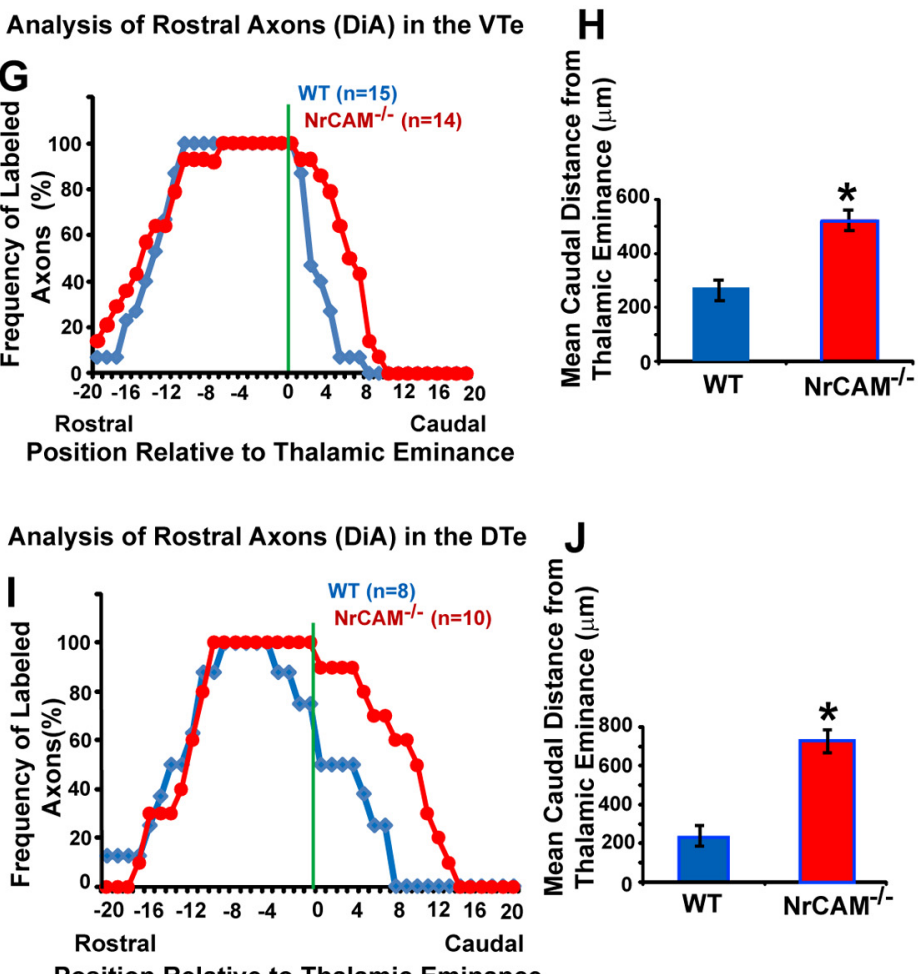

Position Relative to Thalamic Eminance

Figure 3. Rostral thalamic axons of NrCAM-null embryos are caudally shifted in the ventral and dorsal telencephalon at E15.5. $\boldsymbol{A}-\boldsymbol{F}$, Anterogradely labeled rostral (DiA) and caudal (Dil) thalamic axons are shown in coronal sections in the VTe or DTe of WT and $\operatorname{NrCAM-null~mutant~embryos~(E15.5)~at~the~following~locations:~at~the~TE~}(\boldsymbol{A}, \boldsymbol{D})$, VTe $500 \mu \mathrm{m}$ caudal to TE $(\boldsymbol{B}, \boldsymbol{E})$, and DTe $700 \mu \mathrm{m}$ caudal to TE $(\boldsymbol{C}, \boldsymbol{F})$. Schemes at right depict the DiA and Dil injection sites and location of sections. $\mathbf{G}-\mathbf{J}$, Quantification of the rostrocaudal distribution of rostral thalamic axons of WT and NrCAM-null embryos in the VTe $(\boldsymbol{G}, \boldsymbol{H})$ and in the DTe $(\boldsymbol{I}, \boldsymbol{J})$. Reference point (0) corresponds to the TE. The frequency (percentage) of hemispheres containing DiA-labeled rostral thalamic axons ( $y$-axis) is plotted versus section number relative to the TE along the rostrocaudal axis (normalized to total number of sections). The mean distance (micrometers) of the caudal-most section from the TE containing DiA-labeled rostral thalamic axons was determined and the SEM calculated for each genotype $\left({ }^{*} p<0.05\right.$, significant difference, $t$ test). I, lateral; m, medial. Scale bar, $100 \mu \mathrm{m}$.

nificantly greater in Npn-2 mutants than Npn-2 heterozygote controls (Fig. $5 E, G, H$ ). The small rostral shift of labeled rostral DT axons in Npn-2 mutants was not significant. Analysis of DiIlabeled caudal DT axons showed no significant differences in distribution in either the VTe or cortex of Npn-2 mutants at E15.5 (data not shown). Thus, Npn-2-null embryos (E15.5) exhibited a phenotype of caudal misprojection of DT axons in the VTe similar to that of NrCAM-null embryos, suggesting that there may be important functional interactions between Npn-2 and NrCAM.
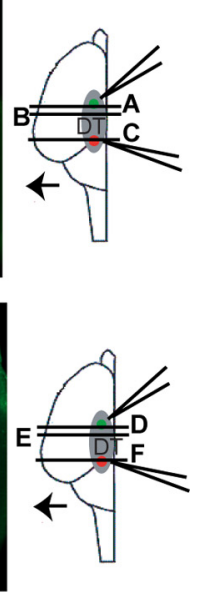

NrCAM mediates Sema3F-induced growth cone collapse of thalamic neurons and associates with neuropilin-2

The posterior shift of motor and somatosensory thalamic axons to the visual cortex in NrCAM-null mutants may be due to impaired repellent of thalamic axon guidance away from the high caudal Sema3F gradient in the VTe, where axons are sorted initially along the rostrocaudal axis to discrete cortical areas (Dufour et al., 2003). To determine whether NrCAM is required for growth cone collapse in thalamic axons in response to Sema3F, growth cone collapse assays were performed using cultures of dissociated thalamic neurons from WT and NrCAM-null mutant embryos (E15.5). Sema3F-Fc induced a pronounced growth cone collapse response in WT thalamic neurons, notably increasing the percentage of collapsed growth cones compared with control treatment with nonimmune IgG (Fig. 6 $A, B, F$ ). In contrast, Sema3F-Fc treatment of NrCAM-null mutant thalamic neurons failed to induce growth cone collapse compared with the control treatment. Basal growth cone collapse in the presence of nonimmune IgG was equivalent for WT and NrCAM-null neurons and was not different from untreated cultures (data not shown). NrCAM was expressed in $58 \%$ of cells in the thalamic cultures and colocalized with Npn-2 in 53\% of cells $(n=62)$. NrCAM immunofluorescence was evident on cell bodies, processes and growth cones of cells with neuronal morphology and was enriched at tips of filopodia (Fig. 6E).

A molecular complex of NrCAM and Npn-2 (characteristic doublet) (Giger et al., 2000) was demonstrated by coimmunoprecipitation from lysates of E15.5 mouse brain (Fig. 6G) in accord with a previous report (Falk et al., 2005). Association of NrCAM and Npn-2 was also demonstrated by antibody-induced coclustering on the cell surface of the mouse neuroblastoma cell line Neuro2A, which we found expresses high levels of endogenous NrCAM, Npn-2, and PlexinA3, a signaling subunit of the Npn-2 receptor complex. Clustering of Npn-2 using antibodies against its extracellular region resulted in coclustering of NrCAM into caps (Fig. $6 H$ ) and patches (Fig. 6I) on the Neuro2A cell surface, consistent with a direct or indirect association. Coclustering was observed in $81 \%$ of cells expressing both NrCAM and Npn2. Nonimmune IgG was used as a control to ensure no cross-reactivity of secondary antibodies (Fig. 6J,K).

In summary, Sema3F-induced growth cone collapse in embryonic thalamic neurons is attenuated by the loss of NrCAM. In addition, NrCAM associated with Npn-2 in embryonic brain and neural cells, where it may function in the Sema3F receptor complex to repel 

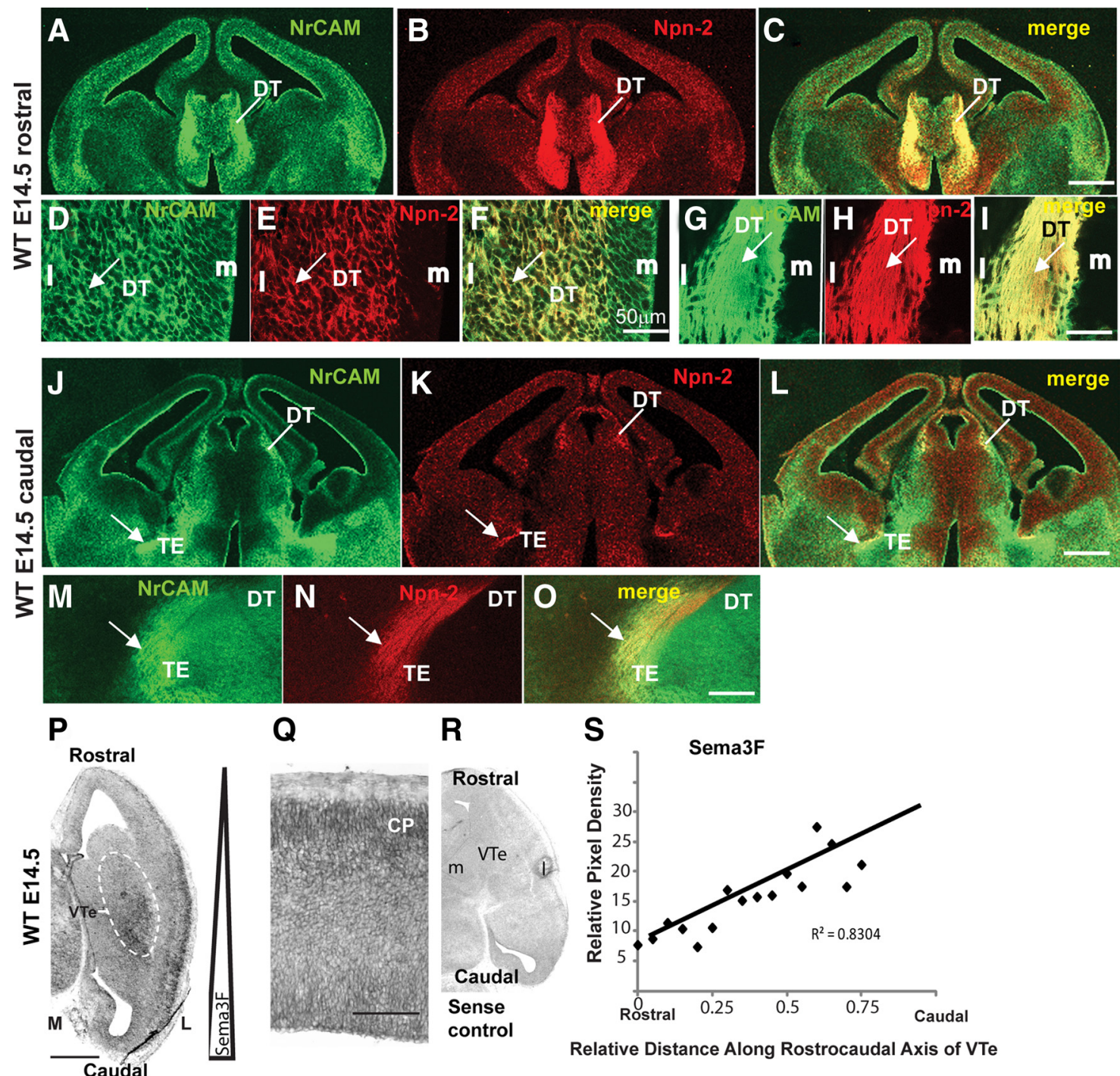

Relative Distance Along Rostrocaudal Axis of VTe

Figure 4. Colocalization of NrCAM and neuropilin-2, and expression of Sema3F in the thalamocortical pathway. $A-L$, Double immunofluorescence staining for NrCAM and Npn-2 in WT embryos (E14.5) showed high levels of expression and colocalization in the rostral $D T(A-C)$ and lower levels of expression in the caudal $D T(J-L$; arrows indicate the TE) in coronal sections. $D-F$, Higher magnification of medial third of the rostral DT, showing colocalization of Npn-2 and NrCAM on cells, and absence of Npn-2 from the extreme medial region. G-I, Higher magnification of the lateral region of the rostral DT showing

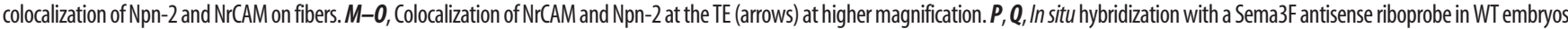
(E14.5) in horizontal sections. Sema3F transcripts were preferentially expressed in the VTe in a high-caudal to low-rostral gradient, and in the developing (P of the cortex. $\boldsymbol{R}$, No labeling was observed with the control sense riboprobe. S, Pixel density was measured along the rostrocaudal axis of the VTe in serial sections from 3 WT embryos (E14.5) using Image Software, normalized to background. The data were fit to a linear regression curve with an $R^{2}$ value of 0.8304 . Abbreviations: I, lateral; m, medial. Scale bar: $(\boldsymbol{A}-\boldsymbol{C}, \boldsymbol{J}-\mathbf{L}, \boldsymbol{P}), 500 \mu \mathrm{m} ;(\boldsymbol{R}), 100 \mu \mathrm{m} ;(\boldsymbol{D}-\mathbf{I}, \mathbf{M}-\mathbf{0}), 50 \mu \mathrm{m}$.

thalamic axons from Sema3F in the VTe important for DT axon sorting.

Normal patterning of thalamic nuclei and cortical areas in NrCAM mutant mice

Nissl staining of NrCAM-null mutant and WT littermates at P7 was used to assess the size and position of DT nuclei at equivalent rostrocaudal levels (Takeuchi et al., 2007). Motor thalamic nuclei (VA, VL), somatosensory VB nuclei, and the dLGN of NrCAMnull mice were appeared normal in size and location compared with WT on coronal sections (Fig. $7 A-D$ ). To compare the patterning of neocortical areas, serotonin (5-HT) histochemistry was performed on tangential (Fig. $7 E, H-J$ ) sections through layer IV of flattened cortical hemispheres and coronal sections (Fig. $7 F, G, K, L$ ) and of NrCAM-null and WT littermates at P7, as described previously (Takeuchi et al., 2007). The location and size of primary cortical areas [S1, V1, auditory cortex) and sec- ondary somatosensory cortex in NrCAM mutants appeared to be equivalent to WT (Fig. $7 E-L$ ). In coronal sections (Fig. $7 F-L$ ), layer IV of S1 and V1 in NrCAM-null mice exhibited a normal location and size. In particular, the length of V1 in coronal sections, measured by 5-HT staining at the level of the posterior commissure, was approximately the same in NrCAM-null $(1117 \pm 74 \mu \mathrm{m}, n=6)$ and WT mice (1262 $\pm 154 \mu \mathrm{m}, n=6)$. Thalamocortical inputs to layer IV of S1 in NrCAM mutants also segregated normally into a barrel field pattern characteristic of WT (Fig. $7 F, H, I, L$ ). Thus, thalamic nuclei and cortical area patterning appeared to be normal in NrCAM mutant mice.

Retinogeniculate axon targeting is unaffected by

NrCAM deletion

Ipsilateral retinal ganglion cell (RGC) axons project from the ventrotemporal retina to the dLGN, where they form an ipsilateral "patch" surrounded by contralateral axon terminations 

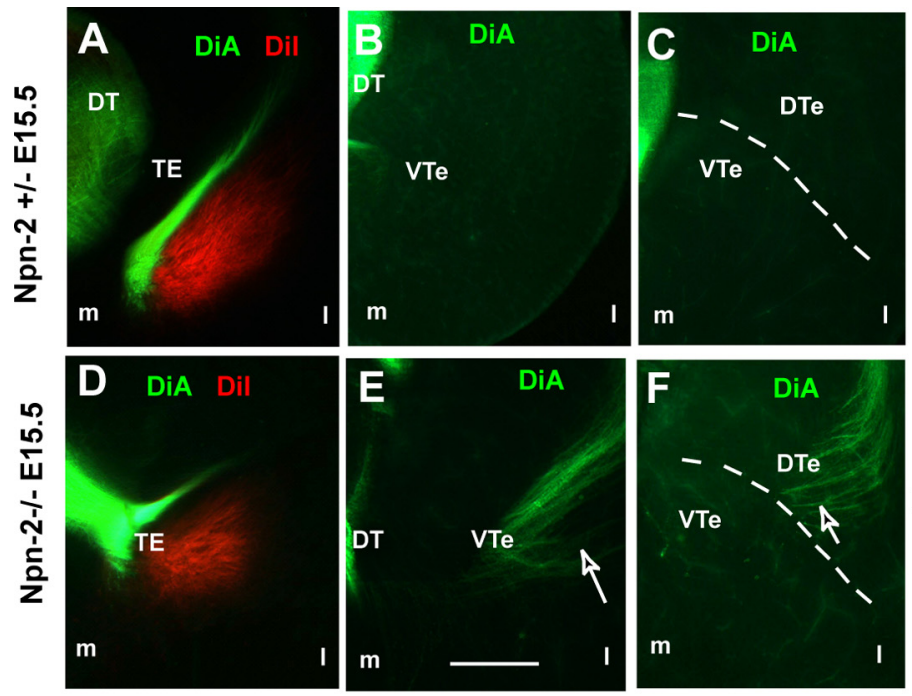

G

Analysis of Rostral Axons (DiA) in the VTe$$
\text { 웜 }
$$

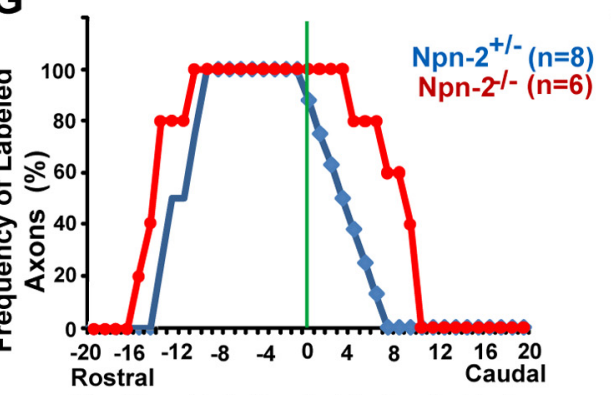

Position Relative to Thalamic Eminance

Analysis of Rostral Axons (DiA) in the DTe
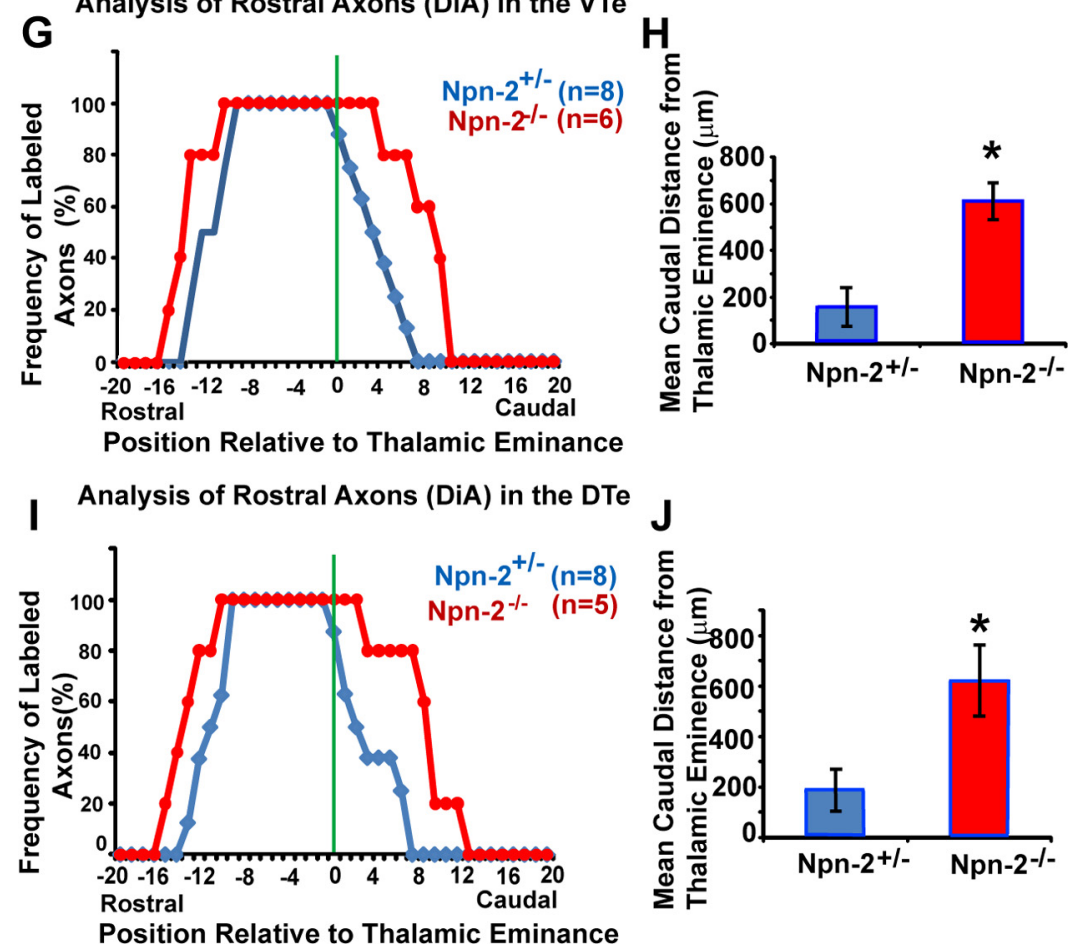

\section{$J$}

Figure 5. Rostral thalamic axons of neuropilin-2-null embryos (E15.5) are caudally shifted in the ventral and dorsal telencephalon. $\boldsymbol{A}-\boldsymbol{F}$, Anterogradely labeled rostral (DiA) and caudal (Dil) thalamic axons are shown in coronal sections through the VTe and DTe of heterozygous and homozygous Npn-2-null mutant embryos (E15.5) at the following locations: the TE (A, D), VTe $500 \mu \mathrm{m}$ caudal to TE $(\boldsymbol{B}, \boldsymbol{E})$, and DTe $600 \mu \mathrm{m}$ caudal to TE $(\boldsymbol{C}, \boldsymbol{F})$. Schemes at right depict DiA and Dil injection sites and planes of sections. Scale bar, $100 \mu \mathrm{m}$. G-J, Quantification of the rostrocaudal distribution of rostral thalamic axons in Npn-2 heterozygotes and null mutant embryos (E15.5) at the VTe $(\mathbf{G}, \boldsymbol{H})$ and DTe $(\boldsymbol{I}, \boldsymbol{J})$. The frequency (percentage) of hemispheres containing DiA-labeled rostral thalamic axons ( $y$-axis) is plotted versus section number relative to the TE along the rostrocaudal axis (normalized to total number of sections). Reference point ( 0 ) corresponds to the TE. The mean distances (micrometers) of the caudal-most section from the TE containing DiA-labeled rostral thalamic axons in the VTe $(\boldsymbol{H})$ or DTe $(\boldsymbol{J})$ was determined for each genotype $\left({ }^{*} p<0.05\right.$, significant difference, $t$ test). I, lateral; $m$, medial.

(Torborg et al., 2005). Most ipsilateral axons project early in development (E14-E16) (Williams et al., 2006). To visualize retinogeniculate targeting and eye-specific segregation, RGC axons of WT and NrCAM-null mutant mice were labeled by injection of cholera toxin B-conjugated Alexa fluorophores (488, green; 594, red) into right and left eyes at P10 (13 WT and 12 NrCAM-null mutant mice). Their termination zones in the dLGN were visualized at P12 (Fig. 8A,B), when most mouse ipsilateral projec-
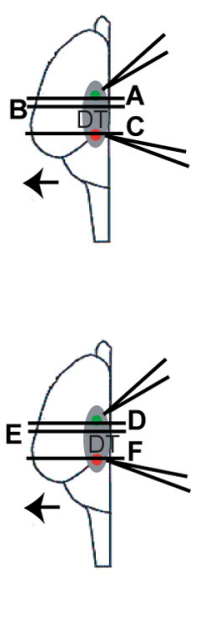

tions have segregated into a patch in the dorsomedial dLGN (Torborg et al., 2005). The area of the ipsilateral patch and total dLGN area were quantified by measurement of pixels within designated areas of fluorescent images using a multithreshold protocol (Torborg et al., 2005; Stevens et al., 2007). The area of the ipsilateral patch relative to total dLGN area in NrCAMnull mice was not significantly different compared with WT mice at all threshold levels (Fig. 8C; $t$ test at each threshold level, $p<0.05$ ). There were also no significant differences in dLGN area, location of the ipsilateral patch, or length of the ipsilateral patch in WT and NrCAM-null mice (Fig. 8D). Thus, loss of NrCAM does not appear to grossly perturb retinogeniculate axon targeting.

\section{Visual cortical function is altered in \\ NrCAM-null mutant mice}

The aberrant migration of thalamic motor and somatosensory afferents to the visual cortex in NrCAM-null mutant mice suggested a potential impact on cortical function. To investigate whether NrCAM loss of function affects how the visual cortex responds to visual stimuli, we recorded VEPs in the binocular zone of the primary visual cortex in awake WT and NrCAMnull mutant littermates at P27. Contralateral and ipsilateral retinogeniculate projections terminate in the dLGN, where they are relayed as thalamocortical projections to the binocular zone of V1 (Fig. $9 A)$. VEPs can be induced by stimulating both eyes with a full field visual stimulus from a display monitor of reversing bars, whose spatial frequency (cycles/degree) is varied, to identify the stimulus that produces a maximal VEP response (Fig. 9B). Stimulation of both eyes produced a larger binocular visual response in $\mathrm{WT}$ mice at $0.3 \mathrm{cpd}$ compared with $0.05 \mathrm{cpd}$, similar to what has been observed in the 129 mouse strain (Fig. 9B) (Yashiro et al., 2009). In contrast, NrCAM-null mutants responded strongly to visual stimulation at the lower spatial frequency of $0.05 \mathrm{cpd}$ and more weakly at $0.3 \mathrm{cpd}$, indicative of reduced visual acuity (Fig. 9B). This difference was quantified by plotting the acuity ratio (VEP amplitude at 0.3/0.05 cpd), which showed a significant decrease in NrCAM mutants $(n=16)$ compared with WT $(n=11)$ mice (Fig. 9C; unpaired Student's $t$ test, $p<0.0001$ ). These results demonstrate that NrCAM is required for the normal maturation of cortical visual acuity.

Next, we examined the extent to which deletion of NrCAM altered visual cortical inputs from the contralateral or ipsilateral eye (relative to the recording electrode). For these experiments, VEPs were examined when either the ipsilateral or contralateral 

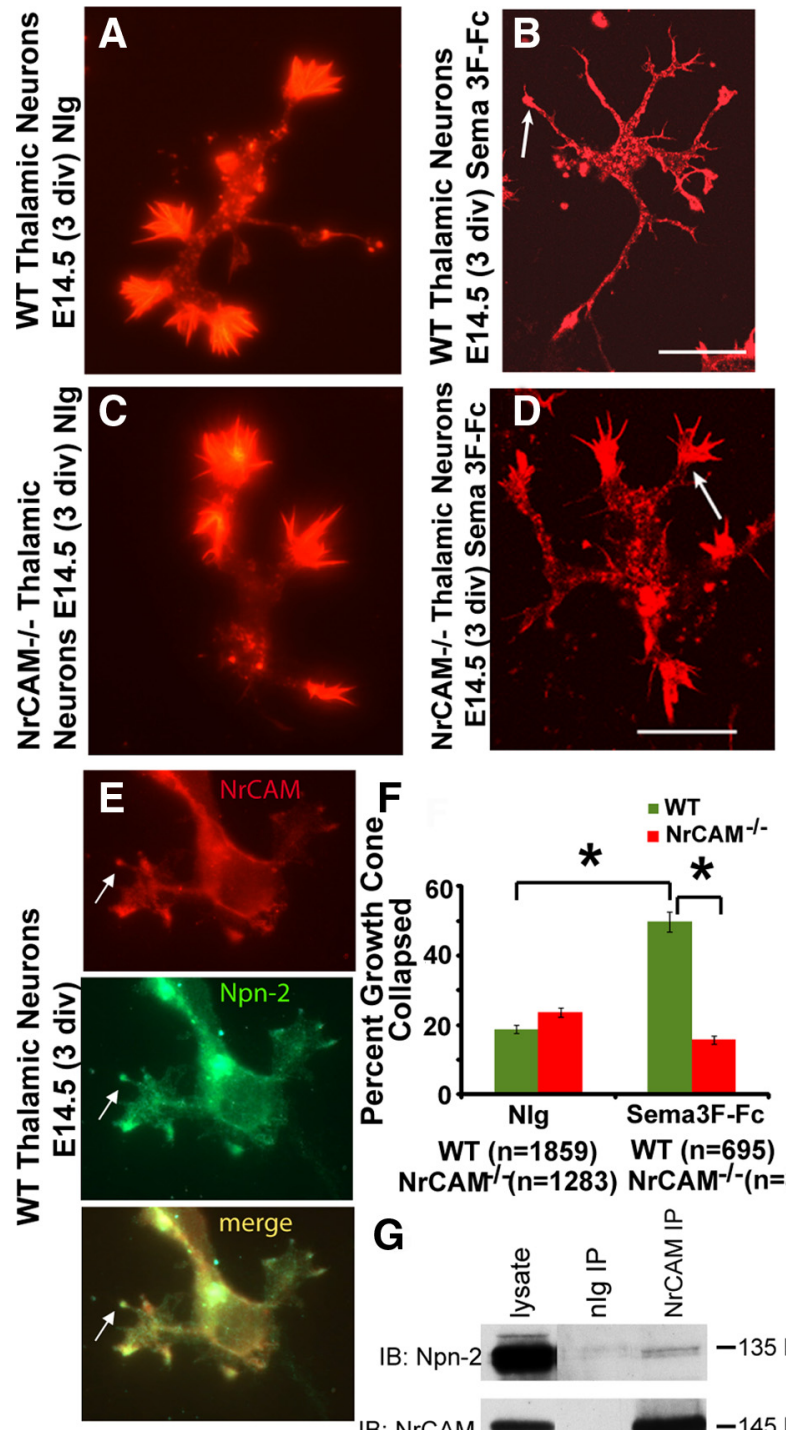

WT $(n=1859) \quad$ WT $(n=695)$ $\operatorname{NrCAM}^{-1}-(n=1283) \operatorname{NrCAM}^{-1-}(n=837)$

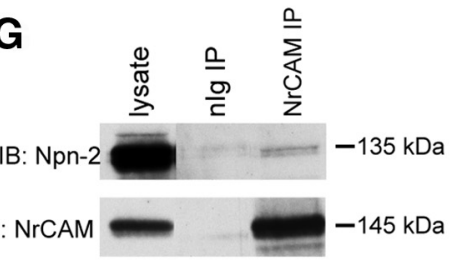

E15.5 brain
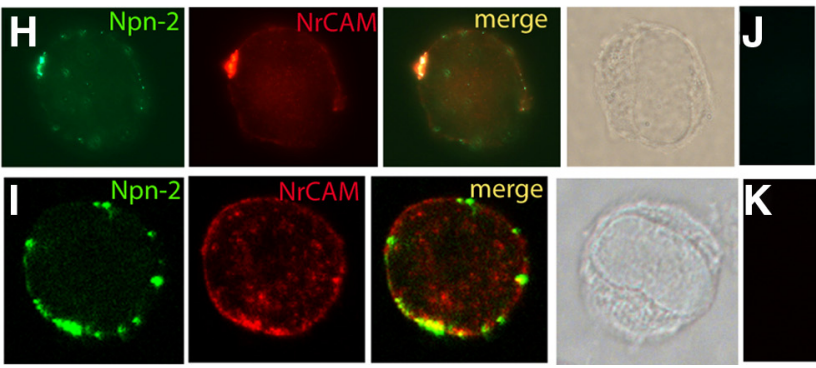

Figure 6. NrCAM is required for Sema3F-induced growth cone collapse in embryonic (E14.5) thalamic neuron cultures. A, C, Representative examples of WT and NrCAM-null mutant noncollapsed growth cones scored following $30 \mathrm{~nm} \mathrm{IgG}$ treatment, fixed and stained with phalloidin. Scale bar, $5 \mu \mathrm{m}$. B, D, Representative examples of WT and NrCAM-null mutant growth cones scored following $30 \mathrm{~nm}$ Sema3F-Fc treatment, fixed and stained with phalloidin. Arrow points to collapsed growth cone in B. Arrow points to noncollapsed growth cone in D. Scale bar, $5 \mu \mathrm{m}$. E, NrCAM and Npn-2 colocalized in embryonic thalamic neurons within processes, soma, and growth cones. Arrows indicate enrichment at tips of filopodia. $F$, Quantification of growth cone collapse in thalamic neurons in response to Sema3F-Fc. Sema3F-Fc significantly increased the percentage of collapsed growth cones in WT but not NrCAM-null mutant neurons compared with nonimmune Ig treatment. Asterisks indicate significant differences in means $(p<0.05$; test). $n=$ number of growth cones scored. G, Coimmunoprecipitation of NrCAM and Npn-2 from E15.5 brain. Extracts of WT (E15.5) forebrain (1 mg) were immunoprecipitated (IP) with $\operatorname{NrCAM}$ antibody $(1 \mu \mathrm{g})$ or normal rabbit lgG $(\mathrm{nlg})$, separated by SDS-PAGE and immunoblotted
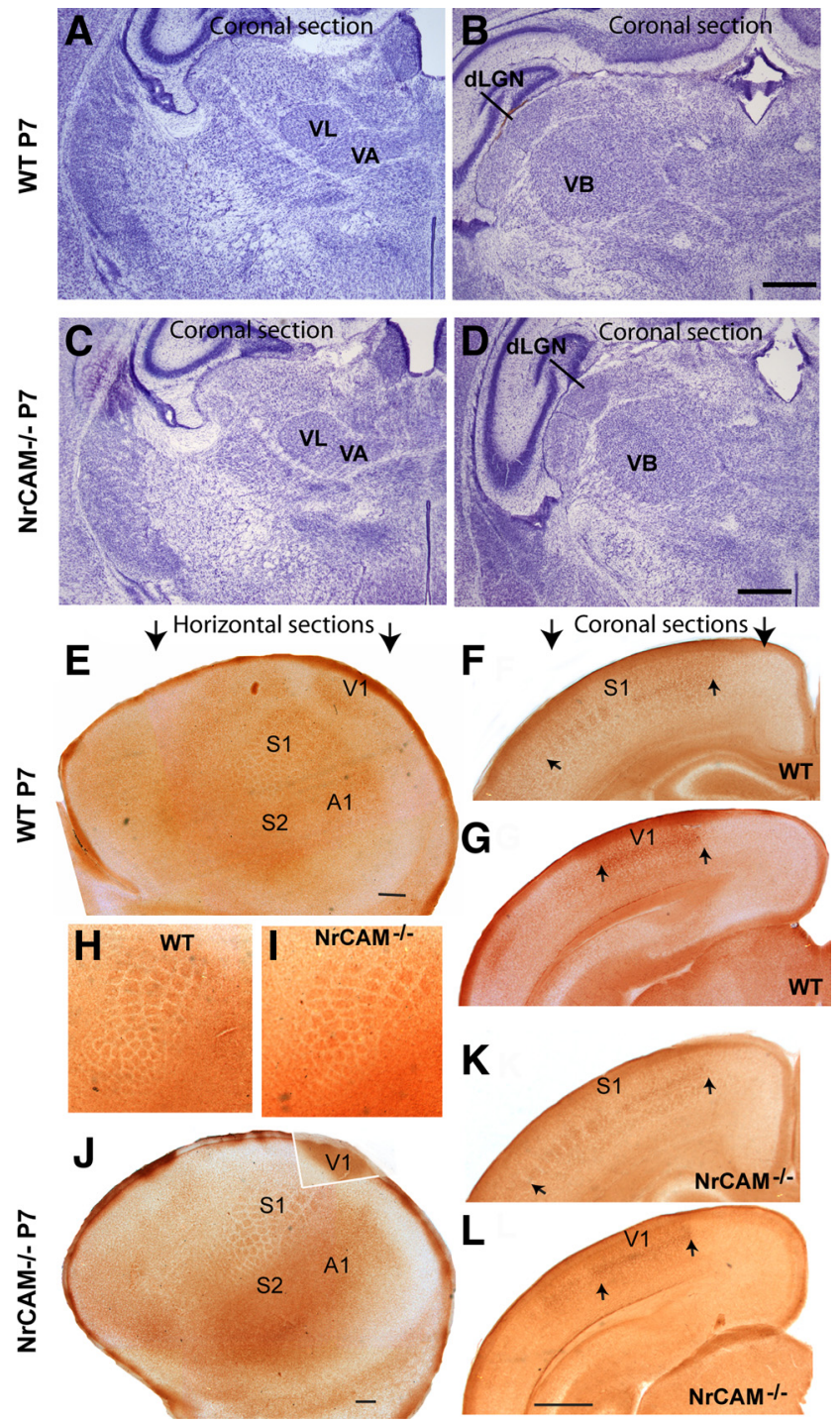

Figure 7. NrCAM-null mutant mice exhibit normal patterning of thalamic nuclei and cortical areas. $\boldsymbol{A}-\boldsymbol{D}$, Nissl staining of coronal sections in WT $(\boldsymbol{A}, \boldsymbol{B})$ and NrCAM-null mutant $(\boldsymbol{C}, \boldsymbol{D})$ mice (P7) shows normal size and locations of dorsal thalamic nuclei (VA/VL, VB, dLGN). E-L, Equivalent area patterning in the cortex of WT $(\boldsymbol{E}-\boldsymbol{H})$ and $\operatorname{NrCAM}$-null mutants $(\boldsymbol{I}-\boldsymbol{L})$ at $P 7$ revealed by 5-HT immunoreactivity. Arrows delineate the barrel field in layer IV of $\mathrm{S} 1(\boldsymbol{F}, \boldsymbol{K})$ and layer IV of V1 $(\mathbf{G}, \boldsymbol{L})$. White lines in J delineate V1 from an adjacent section. A1, primary auditory cortex. Scale bar, $500 \mu \mathrm{m}$.

eye was covered to isolate eye-specific inputs to the binocular zone of V1. Visual stimuli presented to the ipsilateral eye at a low spatial frequency $(0.05 \mathrm{cpd})$ produced similar VEP amplitude in WT and NrCAM-null mutants (Fig. 9D). Visual stimuli at a higher spatial frequency $(0.3 \mathrm{cpd})$ produced a significantly

(IB) using antibodies to Npn-2 (135 kDa). Blots were reprobed with antibodies to NrCAM (145 $\mathrm{kDa}) . \boldsymbol{H}, \boldsymbol{I}$, Coclustering of NrCAM and Npn-2 on the cell surface of the mouse neuroblastoma cell line Neuro2A. Clustering of Npn-2 on the cell surface was induced by treatment of live Neuro2A cells with Npn-2 antibody complexes, then cells were fixed and immunostained for NrCAM using NrCAM antibodies as described in Materials and Methods. Clustering of Npn-2, detected with FITC-labeled secondary antibody (green) and coclustering of NrCAM detected with TRITClabeled secondary antibody (red) were observed by colocalization in caps $(\boldsymbol{H})$ and patches $(\boldsymbol{I})$ on the cell surface in merged images (yellow). Differential interference contrast (DIC) of each cell is shown to the right. $\boldsymbol{J}, \boldsymbol{K}, \mathrm{Goat}(\boldsymbol{J})$ and rabbit $(\boldsymbol{K})$ nonimmune $\lg \boldsymbol{G}$ were substituted for primary antibodies as controls to ensure no cross-reactivity of secondary antibodies. 

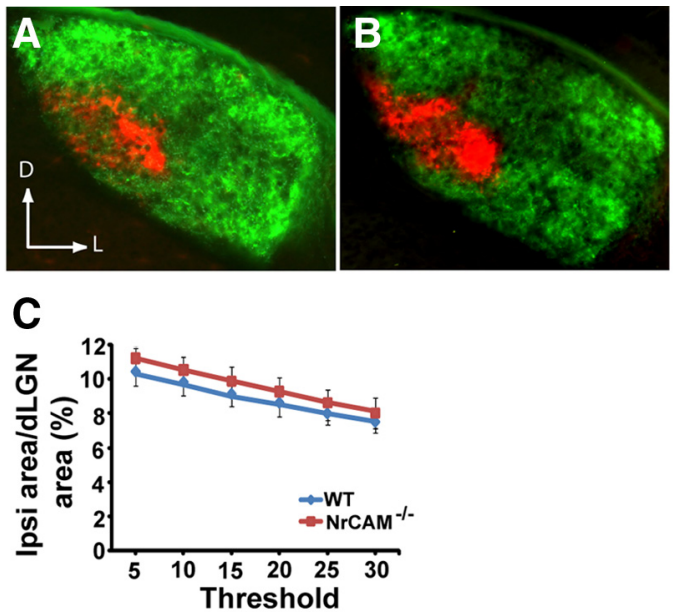

\section{Retinogeniculate Axon Targeting is} Unaffected by NrCAM Deletion

\begin{tabular}{|c|c|c|}
\hline & WT $(n=13)$ & NrCAM- $/-(n=12)$ \\
\hline $\mathrm{dLGN}$ area $\quad\left(\right.$ pixels $\left./ \mathrm{cm}^{2}\right)$ & $5470 \pm 391$ & $5713 \pm 152$ \\
\hline $\begin{array}{l}\text { Ipsi patch distance from dorso- } \\
\text { lateral edge (\% of dLGN width) }\end{array}$ & $41.2 \pm 1.9$ & $42.9 \pm 1.6$ \\
\hline Ipsipatch length (\% dLGN) & $44.6 \pm 1.6$ & $42.5 \pm 1.6$ \\
\hline
\end{tabular}

${ }^{a}$ Statistically not significant (t-test; $\left.p<0.05\right)$

Figure 8. Normal retinogeniculate axon targeting in NrCAM-null mice. Ipsilateral and contralateral projections of retinal axons to the $\mathrm{dLGN}$ were labeled by injection of different cholera toxin B-Alexa fluors into eyes at P10, and termination zones analyzed in the dLGN at P12. $\boldsymbol{A}, \boldsymbol{B}$, Representative overlaid images of ipsilateral (red) and contralateral (green) axons in the dLGN of WT $(\boldsymbol{A})$ mice and NrCAM-null mutant $(\boldsymbol{B})$ mice are shown. $\boldsymbol{C}$, Quantification of the percentage of dLGN area occupied by the ipsilateral axon patch in WT ( $n=$ 13) and $\operatorname{NrCAM}$-null mutants ( $n=12)$ indicated no significant differences for each threshold level ( $p<0.05, t$ test). $\boldsymbol{D}$, Table indicates no quantitative difference in mean dLGN area, or mean location or length of the ipsilateral patch in the dLGN for WT and NrCAM-null mice ( $p<0.05, t$ test).

greater response in WT mice than at $0.05 \mathrm{cpd}(t$ test, $p<0.005)$, but did not provoke an increased response in NrCAM mutants (Fig. 9D). The ipsilateral-eye-evoked response at $0.3 \mathrm{cpd}$ in NrCAM mutants was significantly lower than in WT mice (Fig. 9D; paired Student's $t$ test, $p<0.05)$. WT and NrCAM mutant mice exhibited contralateral-eye responses similar in magnitude to their binocular responses (data not shown).

\section{Discussion}

Here we identified a novel function for NrCAM and the Sema3F receptor Npn-2 in guiding thalamocortical axon subpopulations to specific neocortical areas at the ventral telencephalon, a pivotal intermediate sorting target. Loss of NrCAM or Npn-2 caused rostral embryonic thalamic axons to shift caudally in the VTe, suggesting that NrCAM works in concert with Npn-2 to repel thalamic axon contingents from Sema3F. Supporting this subcortical mechanism, NrCAM formed a molecular complex with Npn-2, and was required for growth cone collapse to Sema3F in thalamic neuron cultures. Strikingly, loss of NrCAM caused motor and somatosensory thalamic axons to misproject to the visual cortex, altering the final topographic map. NrCAM loss of function also profoundly altered responses of the visual cortex to visual stimuli, revealed by decreased visual acuity and differences in ocularity.
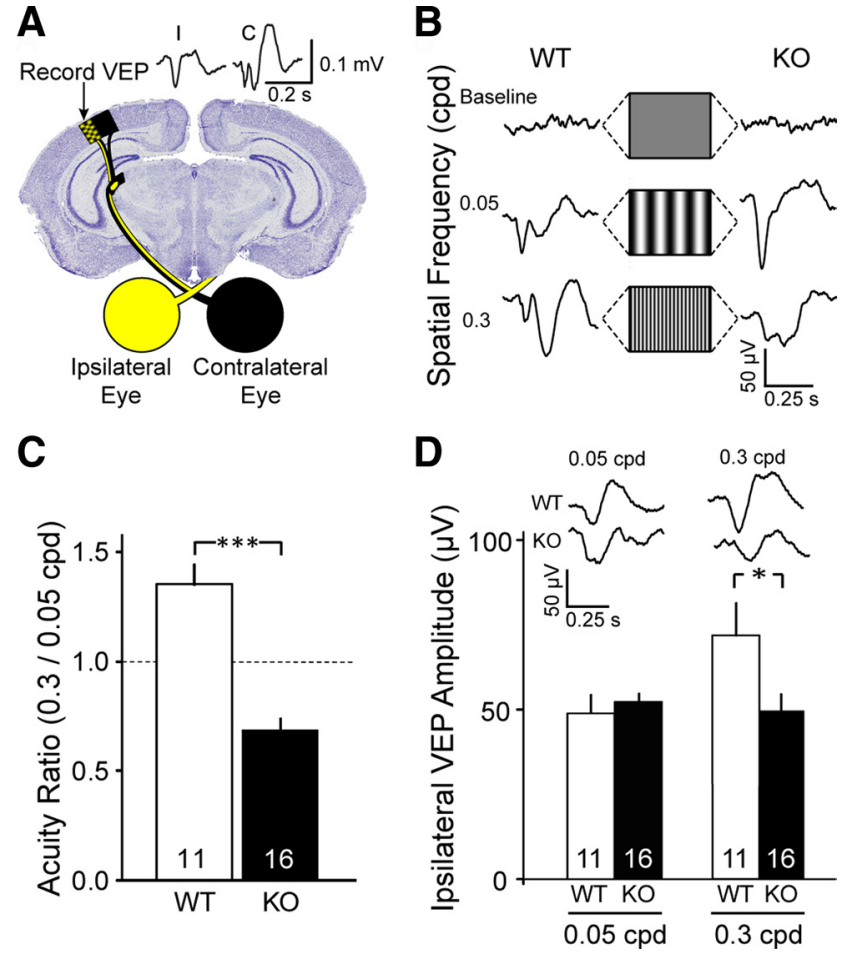

Figure 9. Genetic deletion of NrCAM alters visually driven responses in primary visual cortex. $\boldsymbol{A}$, Schematic demonstrating basic wiring and the recording of VEPs in binocular visual cortex. $\boldsymbol{B}$, Representative VEPs in P27 WT or NrCAM-null mutant mice (KO) evoked by binocular presentations of sinusoidal gratings at 0.05 or $0.3 \mathrm{cpd}$. C, Quantification of the binocularly driven VEPs demonstrates that, unlike WT mice, NrCAM-null mutant mice have larger VEP responses to stimuli presented at $0.05 \mathrm{cpd}$ than at $0.3 \mathrm{cpd}(t$ test, $p<0.0001)$. D, Compared with NrCAM-null mutant mice, WT mice exhibit a larger VEP driven by stimulation of the ipsilateral at $0.3 \mathrm{cpd}$ eye (WT 0.05 cpd vs 0.3 cpd paired $t$ test, $p<0.005$; WT vs NrCAM-null mutant $t$ test, $p<0.05$ ). No differences in ipsilateral VEP amplitude were observed at $0.05 \mathrm{cpd}$. Error bars represent SEM.

These findings support a new view of axon guidance in which L1 family adhesion molecules interact with different repellent axon guidance receptors, and potentially comprise a cell adhesion molecule ("CAM") code regulating topographic mapping of thalamocortical axons. Our findings indicate that NrCAM interaction with Npn-2 mediates a posterior repellent response of rostral thalamic axon subpopulations to Sema3F in the VTe, and that this enables appropriate targeting of motor (VA/VL) and somatosensory (VB) thalamic axon contingents to M1 and S1, respectively. CHL1 interacts with a different receptor, Npn-1, to mediate repulsion of thalamic axon contingents to a Sema3A gradient in the VTe, which enables $\mathrm{S} 1$ targeting of VB axon contingents (Wright et al., 2007), which may be distinct from those regulated by NrCAM. L1 also interacts with Npn-1 and mediates growth cone collapse to Sema3A (Castellani et al., 2000); however, loss of L1 alone does not cause thalamocortical targeting errors (Wiencken-Barger et al., 2004; Demyanenko et al., 2010). Instead, L1 cooperates with CHL1 for topographic targeting of motor thalamic axon contingents from VA/VL to M1, as shown by misprojection of motor thalamic axons to V1 in double mutants (Demyanenko et al., 2010). L1 and CHL1 also associate with different EphA receptors and mediate ephrinA5-induced growth cone collapse (Demyanenko et al., 2010), so they might also functionally interact with ephrinA/EphA guidance systems, which regulate repellent axon guidance of motor thalamic axon contingents at the VTe (Dufour et al., 2006). It is of singular interest that deletion of NrCAM, CHL1, or both $\mathrm{L} 1$ and CHL1 result in caudal mistargeting of different thalamic axon subpopulations to V1. In 
VTe gradients of ephrinA/EphA control sorting of thalamocortical axon contingents to M1 (Dufour et al., 2003), Netrin1/DCC provide a counterforce (Bonnin et al., 2007; Powell et al., 2008), and Neuregulin-1 guides axons across a corridor (López-Bendito et al., 2006). Studies from our group have given rise to a concept that guidance is to semaphorin gradients in the VTe. Because NrCAM, L1, and CHL1 are expressed in different but overlapping patterns in the embryonic DT, they are likely to control guidance of subpopulations of thalamic axons. Differential expression, coupled with the ability of NrCAM and L1/CHL1 to mediate Sema3F or Sema3A responses through Npn-1/2 receptor complexes, respectively, suggests that L1-CAM interactions may serve to increase the specificity of repellent guidance responses in different thalamocortical axon subpopulations within the VTe necessary for correct pathfinding to areaspecific cortical targets.

Our results do not exclude a role for NrCAM in regulating axon guidance within the neocortex, where Sema3F (shown here) and Sema3A (Wright et al., 2007) are expressed. For example, Sema3F was recently shown to regulate axonal projections of dopaminergic neurons in the prefrontal cortex (Kolk et al., 2009) and to specify axon map topography in the olfactory bulb (Takeuchi et al., 2010). By analogy, ephrinAs have cortical and subcortical functions, serving as cues for mapping dLGN axons within the visual cortex (Cang et al., 2005), as well as regulating thalamic axon guidance in the VTe (Dufour et al., 2006). NrCAM expressed in deep layer cortical neurons might also affect corticothalamic axon guidance, which is postulated to reciprocally influence thalamocortical axon guidance (Molnár and Blakemore, 1995).

Our results implicate NrCAM in repellent responses to the Sema3F gradient in the VTe to regulate thalamic axon sorting. Among the secreted class 3 semaphorins (Sema3A-G) only Sema3F (shown here) and Sema3A (Wright et al., 2007) are expressed at significant levels in the VTe at E15.5 (Brain Gene Expression Map (BGEM), St. Jude Children's Research Hospital: http:// www.stjudebgem.org; and Allen Institute for Brain Science: http:// developingmouse.brain-map.org). Although NrCAM can mediate Sema3B signaling through Npn-2, which is important in positioning the anterior commissure (Falk et al., 2005), Sema3B is not expressed in the VTe at E15.5, which has been shown in Sema3B bacterial artificial chromosome (BAC) transgenic mice carrying an enhanced green fluorescent protein reporter (Gong et al., 2003). However, certain transmembrane semaphorins (Sema4A, C-G, Sema5B, and Sema6A-D) are expressed in the E15.5 VTe (Allen Institute for Brain Science: http://developingmouse.brain-map.org), where they might influence thalamic axon guidance.

Our findings that the loss of NrCAM impairs visual acuity and ocularity indicates that visual cortical wiring critically depends upon NrCAM expression. The preferential decrease in ipsilateral visual responses could be due to (1) fewer or weaker ipsilateraleye inputs to the visual cortex binocular zone, (2) a dispersion of ipsilateral-eye inputs to a broader region of the visual cortex, (3) mistargeting of ipsilateral eye inputs, and/or (4) other defects in the retinogeniculocortical pathway. Notably, many aspects of visual system development appeared grossly normal in the absence of NrCAM, including the retinogeniculate axon targeting, eyespecific segregation within the dLGN, and areal targeting of geniculocortical pathways. In NrCAM-null mice, a subpopulation of contralaterally projecting axons from the retina fails to cross the chiasm and instead misprojects ipsilaterally at later stages (E17-P0) (Falk et al., 2005; Williams et al., 2006) than when most ipsilateral axons project to the dLGN (E14-E16) (Falk et al.,
2005; Williams et al., 2006). Since NrCAM-null mutants did not show evidence for gross mistargeting of ipsilateral or contralateral projections within the dLGN, when analyzed postnatally, retinal axons that misproject at the chiasm may represent a relatively small population; alternatively, these axons may not reach the dLGN or are eliminated. Our observation of reduced ipsilateral eye responsiveness in the absence of NrCAM also does not accord with an excess of ipsilateral input to the dLGN. It is more likely that thalamocortical errors, rather than retinogeniculate errors contribute to the aberrant visual acuity. For example, motor and somatosensory thalamic axons that mistarget to the visual cortex in NrCAM-deficient mice might compete with dLGN inputs within layer IV, disrupting ipsilateral eye visual responses. It is unlikely that the ectopic projections observed in NrCAM-null mice at P5-P8 are corrected in adulthood, restoring visual function. Thalamocortical connectivity is established by $\mathrm{P} 4-\mathrm{P} 8$, as shown in the mouse somatosensory cortex (Agmon et al., 1995), and impaired visual evoked responses of NrCAM-null mutants were clearly evident at P27. Although future investigations are needed to identify the precise mechanisms involved, it is clear that the loss of NrCAM severely disrupts normal visual processing in a mouse model.

The aberrant thalamocortical mapping and visual cortical responses observed in NrCAM-deficient mice are consistent with abnormal visual function (Milne et al., 2009a,b; Isler et al., 2010) and altered thalamocortical connectivity in both visual (Mizuno et al., 2006) and sensorimotor systems (Mostofsky et al., 2009) in ASD. Such deficits might reflect impaired functional interaction of NrCAM with Npn-2 during development, resulting in axon guidance errors and abnormal visual circuitry in the cortex. In this regard it is interesting that Npn-2 gene polymorphisms have been associated with autism in a Chinese Han population (Wu et al., 2007). Aberrant visual connectivity and cortical responses may also contribute to social impairments characteristically associated with ASD. Loss of sociability and deficits in reversal learning in NrCAM-null mice (Moy et al., 2009a) recapitulate aspects of the ASD phenotype, thus further investigation on the developmental role of NrCAM may illuminate the abnormal circuitry underlying visual and social deficits found in ASD and other disorders.

\section{References}

Agmon A, Yang LT, Jones EG, O’Dowd DK (1995) Topological precision in the thalamic projection to neonatal mouse barrel cortex. J Neurosci 15:549-561.

Baron-Cohen S, Ashwin E, Ashwin C, Tavassoli T, Chakrabarti B (2009) Talent in autism: hyper-systemizing, hyper-attention to detail and sensory hypersensitivity. Philos Trans R Soc Lond B Biol Sci 364:1377-1383.

Bonnin A, Torii M, Wang L, Rakic P, Levitt P (2007) Serotonin modulates the response of embryonic thalamocortical axons to netrin-1. Nat Neurosci 10:588-597.

Cang J, Kaneko M, Yamada J, Woods G, Stryker MP, Feldheim DA (2005) Ephrin-as guide the formation of functional maps in the visual cortex. Neuron 48:577-589.

Cang J, Wang L, Stryker MP, Feldheim DA (2008) Roles of ephrin-as and structured activity in the development of functional maps in the superior colliculus. J Neurosci 28:11015-11023.

Castellani V, Chédotal A, Schachner M, Faivre-Sarrailh C, Rougon G (2000) Analysis of the L1-deficient mouse phenotype reveals cross-talk between Sema3A and L1 signaling pathways in axonal guidance. Neuron 27:237-249.

Caviness VS Jr, Frost DO (1980) Tangential organization of thalamic projections to the neocortex in the mouse. J Comp Neurol 194:335-367.

Colbert MC, Rubin WW, Linney E, LaMantia AS (1995) Retinoid signaling and the generation of regional and cellular diversity in the embryonic mouse spinal cord. Dev Dyn 204:1-12. 
Conacci-Sorrell M, Kaplan A, Raveh S, Gavert N, Sakurai T, Ben-Ze'ev A (2005) The shed ectodomain of Nr-CAM stimulates cell proliferation and motility, and confers cell transformation. Cancer Res 65:11605-11612.

Davey F, Hill M, Falk J, Sans N, Gunn-Moore FJ (2005) Synapse associated protein 102 is a novel binding partner to the cytoplasmic terminus of neurone-glial related cell adhesion molecule. J Neurochem 94:1243-1253.

Demyanenko GP, Tsai AY, Maness PF (1999) Abnormalities in neuronal process extension, hippocampal development, and the ventricular system of L1 knock-out mice. J Neurosci 19:4907-4920.

Demyanenko GP, Siesser PF, Wright AG, Brennaman LH, Bartsch U, Schachner M, Maness PF (2010) L1 and CHL1 cooperate in thalamocortical axon targeting. Cereb Cortex. Advance online publication. PMID: 20576928.

Dirks P, Thomas U, Montag D (2006) The cytoplasmic domain of NrCAM binds to PDZ domains of synapse-associated proteins SAP90/PSD95 and SAP97. Eur J Neurosci 24:25-31.

Docherty SJ, Davis OS, Kovas Y, Meaburn EL, Dale PS, Petrill SA, Schalkwyk LC, Plomin R (2010) A genome-wide association study identifies multiple loci associated with mathematics ability and disability. Genes Brain Behav 9:234-247.

Dufour A, Seibt J, Passante L, Depaepe V, Ciossek T, Frisén J, Kullander K, Flanagan JG, Polleux F, Vanderhaeghen P (2003) Area specificity and topography of thalamocortical projections are controlled by ephrin/Eph genes. Neuron 39:453-465.

Dufour A, Egea J, Kullander K, Klein R, Vanderhaeghen P (2006) Genetic analysis of EphA-dependent signaling mechanisms controlling topographic mapping in vivo. Development 133:4415-4420.

Falk J, Julien F, Bechara A, Fiore R, Nawabi H, Zhou H, Hoyo-Becerra C, Bozon M, Rougon G, Grumet M, Püschel AW, Sanes JR, Castellani V (2005) Dual functional activity of semaphorin $3 \mathrm{~B}$ is required for positioning the anterior commissure. Neuron 48:63-75.

Franklin KBJ, Paxinos G (1997) The mouse brain in stereotaxic coordinates. San Diego: Academic.

Giger RJ, Urquhart ER, Gillespie SK, Levengood DV, Ginty DD, Kolodkin AL (1998) Neuropilin-2 is a receptor for semaphorin IV: insight into the structural basis of receptor function and specificity. Neuron 21:1079-1092.

Giger RJ, Cloutier JF, Sahay A, Prinjha RK, Levengood DV, Moore SE, Pickering S, Simmons D, Rastan S, Walsh FS, Kolodkin AL, Ginty DD, Geppert M (2000) Neuropilin-2 is required in vivo for selective axon guidance responses to secreted semaphorins. Neuron 25:29-41.

Gong S, Zheng C, Doughty ML, Losos K, Didkovsky N, Schambra UB, Nowak NJ, Joyner A, Leblanc G, Hatten ME, Heintz N (2003) A gene expression atlas of the central nervous system based on bacterial artificial chromosomes. Nature 425:917-925.

Hardan AY, Minshew NJ, Melhem NM, Srihari S, Jo B, Bansal R, Keshavan MS, Stanley JA (2008) An MRI and proton spectroscopy study of the thalamus in children with autism. Psychiatry Res 163:97-105.

Ishiguro H, Liu QR, Gong JP, Hall FS, Ujike H, Morales M, Sakurai T, Grumet M, Uhl GR (2006) NrCAM in addiction vulnerability: positional cloning, drug-regulation, haplotype-specific expression, and altered drug reward in knockout mice. Neuropsychopharmacology 31:572-584.

Isler JR, Martien KM, Grieve PG, Stark RI, Herbert MR (2010) Reduced functional connectivity in visual evoked potentials in children with autism spectrum disorder. Clin Neurophysiol 121:2035-2043.

Kolk SM, Gunput RA, Tran TS, van den Heuvel DM, Prasad AA, Hellemons AJ, Adolfs Y, Ginty DD, Kolodkin AL, Burbach JP, Smidt MP, Pasterkamp RJ (2009) Semaphorin $3 \mathrm{~F}$ is a bifunctional guidance cue for dopaminergic axons and controls their fasciculation, channeling, rostral growth, and intracortical targeting. J Neurosci 29:12542-12557.

Little GE, López-Bendito G, Rünker AE, García N, Piñon MC, Chédotal A, Molnár Z, Mitchell KJ (2009) Specificity and plasticity of thalamocortical connections in Sema6A mutant mice. PLoS Biol 7:e98.

Lopez-Bendito G, Molnar Z (2003) Thalamocortical development: how are we going to get there? Nat Rev Neuroscience 4:276-289.

López-Bendito G, Cautinat A, Sánchez JA, Bielle F, Flames N, Garratt AN, Talmage DA, Role LW, Charnay P, Marín O, Garel S (2006) Tangential neuronal migration controls axon guidance: a role for neuregulin-1 in thalamocortical axon navigation. Cell 125:127-142.

Lustig M, Erskine L, Mason CA, Grumet M, Sakurai T (2001) Nr-CAM expression in the developing mouse nervous system: ventral midline structures, specific fiber tracts, and neuropilar regions. J Comp Neurol 434:13-28.

Maness PF, Schachner M (2007) Neural recognition molecules of the immunoglobulin superfamily: signaling transducers of axon guidance and neuronal migration. Nat Neurosci 10:19-26.

Matzel LD, Babiarz J, Townsend DA, Grossman HC, Grumet M (2008) Neuronal cell adhesion molecule deletion induces a cognitive and behavioral phenotype reflective of impulsivity. Genes Brain Behav 7:470-480.

Milne E, Scope A, Pascalis O, Buckley D, Makeig S (2009a) Independent component analysis reveals atypical electroencephalographic activity during visual perception in individuals with autism. Biol Psychiatry 65:22-30.

Milne E, Griffiths H, Buckley D, Scope A (2009b) Vision in children and adolescents with autistic spectrum disorder: evidence for reduced convergence. J Autism Dev Disord 39:965-975.

Mizuno A, Villalobos ME, Davies MM, Dahl BC, Müller RA (2006) Partially enhanced thalamocortical functional connectivity in autism. Brain Res 1104:160-174

Molnár Z, Blakemore C (1995) How do thalamic axons find their way to the cortex? Trends Neurosci 18:389-397.

Mostofsky SH, Powell SK, Simmonds DJ, Goldberg MC, Caffo B, Pekar JJ (2009) Decreased connectivity and cerebellar activity in autism during motor task performance. Brain 132:2413-2425.

Moy SS, Nadler JJ, Young NB, Nonneman RJ, Grossman AW, Murphy DL, D'Ercole AJ, Crawley JN, Magnuson TR, Lauder JM (2009a) Social approach in genetically engineered mouse lines relevant to autism. Genes Brain Behav 8:129-142.

Moy SS, Nonneman RJ, Young NB, Demyanenko GP, Maness PF (2009b) Impaired sociability and cognitive function in Nrcam-null mice. Behav Brain Res 205:123-131.

Pinto D, Pagnamenta AT, Klei L, Anney R, Merico D, Regan R, Conroy J, Magalhaes TR, Correia C, Abrahams BS, Almeida J, Bacchelli E, Bader GD, Bailey AJ, Baird G, Battaglia A, Berney T, Bolshakova N, Bölte S, Bolton PF, et al. (2010) Functional impact of global rare copy number variation in autism spectrum disorders. Nature 466:368-372.

Powell AW, Sassa T, Wu Y, Tessier-Lavigne M, Polleux F (2008) Topography of thalamic projections requires attractive and repulsive functions of Netrin-1 in the ventral telencephalon. PLoS Biol 6:e116.

Pruss T, Niere M, Kranz EU, Volkmer H (2004) Homophilic interactions of chick neurofascin in trans are important for neurite induction. Eur J Neurosci 20:3184-3188.

Sakurai T, Lustig M, Nativ M, Hemperly JJ, Schlessinger J, Peles E, Grumet M (1997) Induction of neurite outgrowth through contactin and Nr-CAM by extracellular regions of glial receptor tyrosine phosphatase beta. J Cell Biol 136:907-918.

Sakurai T, Lustig M, Babiarz J, Furley AJ, Tait S, Brophy PJ, Brown SA, Brown LY, Mason CA, Grumet M (2001) Overlapping functions of the cell adhesion molecules $\mathrm{Nr}-\mathrm{CAM}$ and L1 in cerebellar granule cell development. J Cell Biol 154:1259-1273.

Stevens B, Allen NJ, Vazquez LE, Howell GR, Christopherson KS, Nouri N, Micheva KD, Mehalow AK, Huberman AD, Stafford B, Sher A, Litke AM, Lambris JD, Smith SJ, John SW, Barres BA (2007) The classical complement cascade mediates CNS synapse elimination. Cell 131:1164-1178.

Takarae Y, Minshew NJ, Luna B, Sweeney JA (2007) Atypical involvement of frontostriatal systems during sensorimotor control in autism. Psychiatry Res 156:117-127.

Takeuchi A, Hamasaki T, Litwack ED, O'Leary DD (2007) Novel IgCAM, MDGA1, expressed in unique cortical area- and layer-specific patterns and transiently by distinct forebrain populations of Cajal-Retzius neurons. Cereb Cortex 17:1531-1541.

Takeuchi H, Inokuchi K, Aoki M, Suto F, Tsuboi A, Matsuda I, Suzuki M, Aiba A, Serizawa S, Yoshihara Y, Fujisawa H, Sakano H (2010) Sequential arrival and graded secretion of Sema3F by olfactory neuron axons specify map topography at the bulb. Cell 141:1056-1067.

Tamamaki N (2002) Radial glias and radial fibers: what is the function of radial fibers? Anat Sci Int 77:2-11.

Torborg CL, Hansen KA, Feller MB (2005) High frequency, synchronized bursting drives eye-specific segregation of retinogeniculate projections. Nat Neurosci 8:72-78. 
Torii M, Levitt P (2005) Dissociation of corticothalamic and thalamocortical axon targeting by an EphA7-mediated mechanism. Neuron 48:563-575.

Volkmer H, Leuschner R, Zacharias U, Rathjen FG (1996) Neurofascin induces neurites by heterophilic interactions with axonal NrCAM while NrCAM requires F11 on the axonal surface to extend neurites. J Cell Biol 135:1059-1069.

Walz A, Rodriguez I, Mombaerts P (2002) Aberrant sensory innervation of the olfactory bulb in neuropilin-2 mutant mice. J Neurosci 22:4025-4035.

Wiencken-Barger AE, Mavity-Hudson J, Bartsch U, Schachner M, Casagrande VA (2004) The role of L1 in axon pathfinding and fasciculation. Cereb Cortex 14:121-131.

Williams SE, Grumet M, Colman DR, Henkemeyer M, Mason CA, Sakurai T
(2006) A Role for Nr-CAM in the Patterning of Binocular Visual Pathways. Neuron 50:535-547.

Wright AG, Demyanenko GP, Powell A, Schachner M, Enriquez-Barreto L, Tran TS, Polleux F, Maness PF (2007) Close homolog of L1 and neuropilin 1 mediate guidance of thalamocortical axons at the ventral telencephalon. J Neurosci 27:13667-13679.

Wu S, Yue W, Jia M, Ruan Y, Lu T, Gong X, Shuang M, Liu J, Yang X, Zhang D (2007) Association of the neuropilin-2 (NRP2) gene polymorphisms with autism in Chinese Han population. Am J Med Genet B Neuropsychiatr Genet 144B:492-495.

Yashiro K, Riday TT, Condon KH, Roberts AC, Bernardo DR, Prakash R, Weinberg RJ, Ehlers MD, Philpot BD (2009) Ube3a is required for experience-dependent maturation of the neocortex. Nat Neurosci 12:777-783. 